Research Article

\title{
Polyoxometalate functionalized matrix material: synthesis, characterization, reductive and thermal degradation kinetics
}

\author{
C. Sabarinathan ${ }^{1} \cdot$ C. T. Vijayakumar ${ }^{2} \cdot$ T. Arumuganathan $^{1}$
}

Received: 27 December 2019 / Accepted: 2 March 2020 / Published online: 13 March 2020

(c) Springer Nature Switzerland AG 2020

\begin{abstract}
One-pot synthesis of polyoxometalate (POM) based hybrid material 1 was synthesized by mixing copper nitrate, silicomolybdic acid and urea under hydrothermal condition. The reduction ability of 1 was examined by employing 2,4,6-trinitrophenol (2,4,6-TNP) and 4-nitrophenol (4-NP) in the presence of sodium borohydride in water. The catalytic reduction into the corresponding amine was monitored by UV-Visible spectroscopy. The rate and order of catalytic reduction were studied through chemical kinetics and follows pseudo-first-order. The efficiency of the catalyst was investigated by employing used catalyst $\mathbf{1}$ for at least ten cycles. Leaching experiments and performance of the reusability of catalyst were supported by FT-IR analyses. In addition, the electrochemical reduction ability of catalyst 1 was also executed by Cyclic Voltammetry (CV). Catalyst 1 was characterized by Fourier-Transform Infrared spectroscopy (FT-IR), Powder X-ray diffraction (PXRD), UV-Diffused Reflectance (UV DRS), Scanning Electron Microscope (SEM), Energy Dispersive X-ray Spectroscopy (EDX), X-ray Photoelectron Spectroscopy (XPS), and Bruner-Emmet-Teller analyses (BET). Solid-state decomposition kinetics of $\mathbf{1}$ was performed from Thermogravimetric Analysis (TGA) data by fitting into model equations such as Flynn-Wall-Ozawa (FWO) and corrected (C-FWO).
\end{abstract}

Electronic supplementary material The online version of this article (https://doi.org/10.1007/s42452-020-2396-x) contains supplementary material, which is available to authorized users.

T. Arumuganathan, arumuganathan_chem@tcarts.in | 'Department of Chemistry, Thiagarajar College, Madurai, Tamilnadu 625009 , India. ${ }^{2}$ Department of Polymer Technology, Kamaraj College of Engineering and Technology, K. Vellakulam, Madurai, Tamilnadu 625701 , India. 


\section{Graphic abstract}<smiles>O=[N+]([O-])c1cc([N+](=O)[O-])c(O)c([N+](=O)[O-])c1</smiles>

2,4,6-trinitrophenol (2,4,6-TNP)
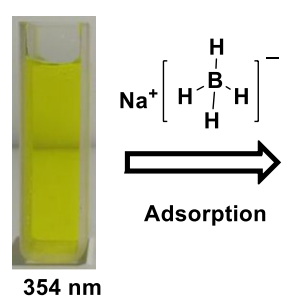

$354 \mathrm{~nm}$<smiles>Nc1cc(N)c(O)c(N)c1</smiles>

2,4,6-triaminophenol (2,4,6-TAP)

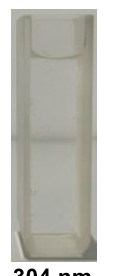

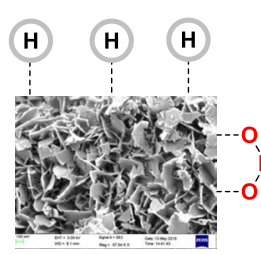
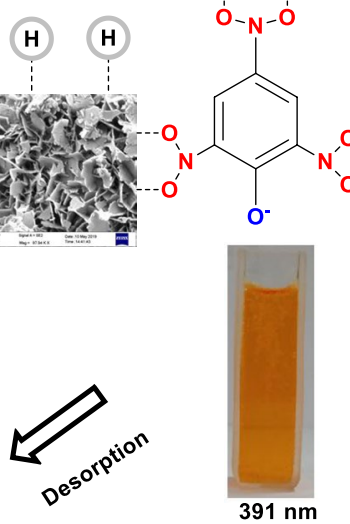

$391 \mathrm{~nm}$

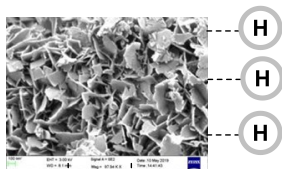

$0-n-O$

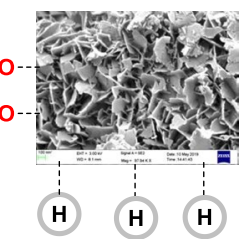

H H $\mathrm{H}$

Keywords Inorganic-organic hybrid composite - Reductive hydrogenation kinetics - Nitro phenol derivatives in aqueous $\cdot$ Heterogeneous $\cdot$ Thermal degradation kinetics

\section{Introduction}

The aromatic amine compounds are needed for synthetic organic chemists because of their wide spectrum of usage in pharmaceutical, agrochemical and dye industries [1]. In most of the cases as bulk/in one of the intermediate step aromatic amines are prepared by reduction of their analogous nitro derivatives. Most of the time, the reduction of nitro moiety became unsuccessful in the case of the presence of other functional groups in the same aromatic ring otherwise needed a selective catalyst for successful conversion. Hence, an attempt of exploring efficient and prominent selective catalyst for the reduction of nitro to amine is highly required one. Nitrophenol (NP) derivatives, especially, the 2,4,6-trinitrophenol (2,4,6-TNP) is an explosive, hazardous and carcinogenic material used in industrial and military applications during the world war. Because of their longer sustainability, the residues of such organic pollutants are difficult to remove from the earth and create adverse environmental issues [2-4]. Moreover, functionalized organic pollutants include $-\mathrm{CHO},-\mathrm{C}=\mathrm{O}$, $-\mathrm{OH}$, etc. can be oxidized by chemical treatments including oxidation, chlorination, ozonization, etc. whereas it would be unsuccessful for nitro derivatives. Such environmental disputes needed to be taken to account seriously. Since water is the primary source of life, its contamination by organic nitro pollutants such as 2-NP, 4-NP, and 2,4,6-TNP must be resolved [5]. As for water treatment, NP derivatives are being acquainted with its toxicity which became as threatening to biodiversity and human health. The seriousness of biodiversity increases further, as the number of a nitro group increases in the aromatic rings. This discussion has been substantiated by the previous report mentioned that risk could be reduced by the suitable conversion of nitrophenol into aminophenol derivative which is comparatively less harmful [6]. It is worth mentioning here, that the reduction of the nitro moiety might be the best way to discard nitrophenol derivatives from the environment. Furthermore, coordination/chelation ability of amine greater than nitro moiety and hence derivatives of earlier can be removed by employing suitable complexation technique. In this aspect, the reduction of organic nitro derivatives into amine derivatives has been attracting significant attention. There are a huge number of heterogeneous catalysts that are reported for the reduction of nitrophenol to aminophenol [7-16], etc. However, each method has its downside such as separation of chemicals, calcination to activate catalysts, number 
of steps in synthesis, reporting with a lower yield, specific and selectivity, etc. [17]. Copious reports were available with gracious metals such as $\mathrm{Pd}$ and Pt catalysts, however, the expensive nature of such metals restrict the common usage $[18,19]$. Hence, the development of a novel simple methodology for the reductive conversion with selectivity is currently required research area [20]. In this present work, we adopt the simple one-pot synthesis route of title compound by hydrothermal technique.

The Polyoxometalates (POM) are metal-oxo clusters of molybdenum, tungsten, and vanadium, etc. attracting considerable interest because of their versatility [21]. The POMs are well known for their usage in multiple fields such as medicine, electronics, magnetism, optics [22], conductance, supramolecular chemistry [23], adsorption [24], antitumor [25], anti-cancer [26], anti-bacterial [27] and catalysis etc. [28]. Usage of POM cluster as a catalyst along with transition metal support in the form of matrix composite could have an added advantage over to either as bare transition metals/plain POM treatment like controlled oxidation, deactivation in air, stopping magnetically induced aggregation, etc. [29-31]. It is worth mentioning that in the presence of $\mathrm{NaBH}_{4}$ the POM has been reported as an efficient reductive catalyst as the reduction concern [32]. In this present work, we report a novel inorganic-organic hybrid composite POM-hybrid (1) material isolated in situ and applied as a reductive catalyst for aromatic nitrophenol derivatives in an aqueous medium.

\section{Experimental section}

\subsection{Materials and methods}

The chemicals such as 4-NP, 2,4,6-TNP, $\mathrm{NaBH}_{4}$, urea, copper(II)nitrate trihydrate, $\mathrm{NaH}_{2} \mathrm{PO}_{4}, \mathrm{Na}_{2} \mathrm{HPO}_{4}$, triethylamine and ethanol were purchased from Merck (99\%), Molychem (98\%), Finar (98\%), Loba (98\%) and Rankem (98\%). The silicomolybdic acid $\left(\mathrm{H}_{4} \mathrm{SiMo}_{12} \mathrm{O}_{40}\right)$ was prepared by following the literature procedure with slight modification [33]. All the chemicals were used without any further purification and double distilled water was used throughout the experiments. A simple stirring method was adopted to carry out the reduction study using $2 \mathrm{MLH}$ Remi magnetic stirrer. The reduction reaction was confirmed and monitored by UV-Visible spectroscopy. SEM-EDX analysis was obtained using e-oxford instruments $50 \mathrm{FE}$ SEM-merlin compact 60-27 and PXRD from powder Bruker D8 advance. The Fourier transform-infrared (FT-IR) spectra were recorded by Thermo scientific iD7 spectrometer and thermogravimetric analysis (TGA) data was obtained from Perkin Elmer-STA 600 model instrument. The TGA measurement carried out under $\mathrm{N}_{2}$ flow between the temperature ranges of $30-800^{\circ} \mathrm{C}$ at the various heating rates as $10,15,20$ and $25^{\circ} \mathrm{C} / \mathrm{min}$. The reduction kinetic data were obtained from the Shimadzu UV-3600 spectrophotometer in the ultraviolet-visible (UV-Visible) range of $200-800 \mathrm{~nm}$. The ESI-Mass spectrum was analyzed by Bruker Compass Data Analysis 4.0. UV-DRS spectrum was analyzed by Agilent technologies model cary 100 UV-Vis.

Cyclic Voltommogram of the 2,4,6-TNP and 4-NP in presence of POM-hybrid (1) was recorded in the $680 \mathrm{Amp}$ Booster model in an aqueous medium. As the supporting electrolyte, $0.1 \mathrm{M}$ solution of PBS $(\mathrm{pH}=7)$ buffer solution prepared by mixing $\mathrm{Na}_{2} \mathrm{HPO}_{4}$ and $\mathrm{NaH}_{2} \mathrm{PO}_{4}$ in an aqueous solution (0.1 M) was used. A Glassy Carbon Electrode (GCE) with a surface area of $0.035 \mathrm{~cm}^{2}$ was used as a working electrode, platinum wire served as the counter electrode and $\mathrm{Ag}$ wire as a reference electrode. The BET analysis of POM-hybrid (1) was performed using Quanta chrome instruments version 5.0 through the nitrogen adsorption at $77.35 \mathrm{~K}$. The sample was analyzed BET isotherm after it degassed at $200^{\circ} \mathrm{C}$ for $12.1 \mathrm{~h}$ in a vacuum $\left(6.58 \times 10^{-5} \mathrm{1} /\right.$ torr). ${ }^{1} \mathrm{H}$ NMR spectrum was analyzed by Bruker Advance III $500 \mathrm{MHz}$. The XPS spectra were recorded by using an X-ray photoelectron spectrometer (XPS) equipped with a multi-

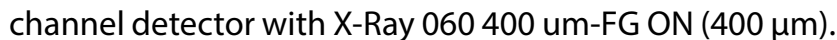

\subsection{Synthesis of inorganic-organic hybrid composite material [POM-hybrid (1)]}

Copper(II)nitrate trihydrate $(0.435 \mathrm{~g}, 1.85 \mathrm{mmol})$ dissolved in $5 \mathrm{~mL}$ of $\mathrm{H}_{2} \mathrm{O}$ was added slowly to $5 \mathrm{~mL}$ of $\mathrm{H}_{2} \mathrm{O}$ in which urea $(0.110 \mathrm{~g}, 1.8 \mathrm{mmol})$ was pre-dissolved. To the resulting solution $\mathrm{H}_{4} \mathrm{SiMo}_{12} \mathrm{O}_{40}(0.100 \mathrm{~g}, 0.054 \mathrm{mmol})$ dissolved in $10 \mathrm{~mL}$ of $\mathrm{H}_{2} \mathrm{O}$ was added slowly and followed by triethylamine $(0.5 \mathrm{~mL})$ was added. The resulting reaction mixture was stirred for $1 \mathrm{~h}$ and later filtered. The title compound formed was washed with water many times and further dried at room temperature to get a greenish-blue powder with a yield of $0.530 \mathrm{~g}$.

\subsection{Chemical catalytic reduction of 2,4,6-TNP and 4-NP in presence of 1}

Reduction reaction was performed by loading 2,4,6-TNP $(100 \mathrm{~mL}, 100 \mathrm{ppm})$ and $\mathrm{NaBH}_{4}(0.050 \mathrm{~g})$ in a round bottom flask and the resulting solution was stirred to obtain 2,4,6-nitrophenolate ion. Composite material 1 (0.050 g) was added to the phenolate solution, as the reaction proceeded, 2,4,6-TNP ion was reduced to 2,4,6-TAP which was monitored and confirmed by simultaneous recording of UV-Visible spectroscopy. In a separate reaction set up, 4-NP was loaded to perform and analyze the reductive catalysis by following the 2,4,6-TNP procedure as 
aforementioned. A similar result was also reported in the literature where nanowire was used as a catalyst [34].

\section{Results and discussion}

\subsection{FT-IR analysis}

The typical FT-IR spectrum of POM-hybrid (1) is shown in Fig. 1. The FT-IR spectrum of $\mathbf{1}$ was confirmed by the presence of urea and $\mathrm{H}_{4} \mathrm{SiMo}_{12} \mathrm{O}_{40}$ by comparing their IR spectrum of each (Fig. 1). The strong stretching frequency at $1453 \mathrm{~cm}^{-1}$ due to $\mathrm{C}-\mathrm{N}$ in the free urea was shifted to $1411 \mathrm{~cm}^{-1}$ in the composite material 1 . Further, the carbonyl stretching of free urea appeared at $1672 \mathrm{~cm}^{-1}$ was shifted to $1607 \mathrm{~cm}^{-1}$ which confirms the covalent bonding of urea to the metal atom. The presence of $\mathrm{H}_{4} \mathrm{SiMo}_{12} \mathrm{O}_{40}$ was characterized by its characteristic stretching such as M-O stretching at $966 \mathrm{~cm}^{-1}$ and $1004 \mathrm{~cm}^{-1}$. Selective important IR stretching frequencies have been put together in Table 1 for better comparison [35-38].

\subsection{PXRD analysis}

The PXRD pattern of POM-hybrid (1) along with starting precursors is shown in Fig. 2. The characteristic peak of urea noticed at 2 theta value $24.54^{\circ}, 31.57^{\circ}$ and $35.42^{\circ}$ have been attributed for their corresponding $h \mathrm{kl}$ plane of (101), (200) and (210) respectively [39] which is shown in Fig. 2a. Similarly, 2 theta values for $\mathrm{Cu}\left(\mathrm{NO}_{3}\right)_{2}$, and $\mathrm{H}_{4} \mathrm{SiMo}_{12} \mathrm{O}_{40}$ were obtained from PXRD profile data and found to be $17.54^{\circ}, 54.99^{\circ}, 60.15^{\circ}$ and $66.46^{\circ}$ [corresponding $\mathrm{hkl}$

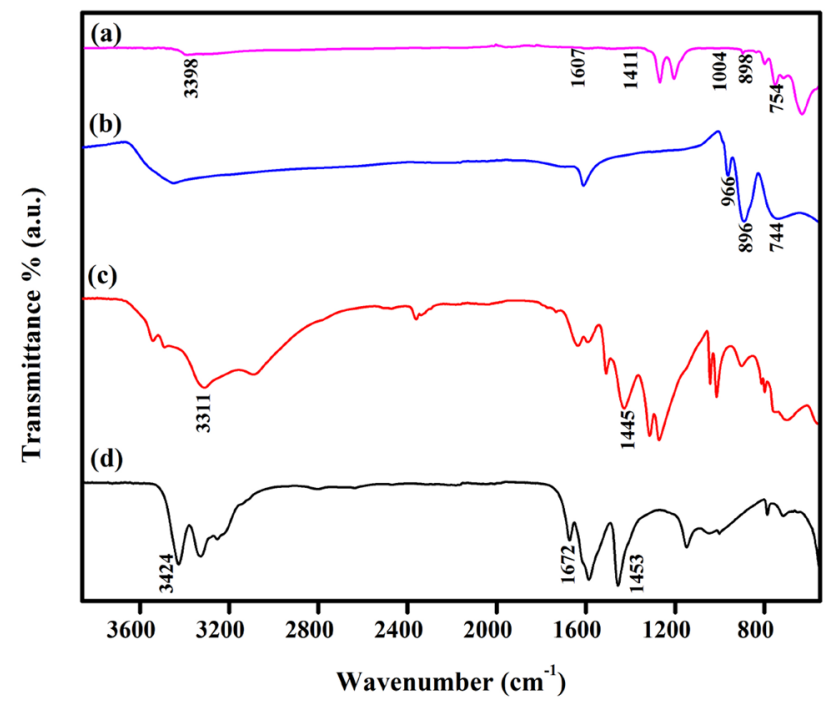

Fig. 1 FT-IR spectra of a POM-hybrid (1), b $\mathrm{H}_{4} \mathrm{SiMo}_{12} \mathrm{O}_{40}$, c $\mathrm{Cu}\left(\mathrm{NO}_{3}\right)_{2} \cdot 3 \mathrm{H}_{2} \mathrm{O}$, d urea

\section{SN Applied Sciences}

Table 1 Important FT-IR data $\left(\mathrm{cm}^{-1}\right)$

\begin{tabular}{lllll}
\hline $\begin{array}{l}\text { Assignment } \\
\text { (functional } \\
\text { groups) }\end{array}$ & Urea & $\mathrm{H}_{4} \mathrm{SiMo}_{12} \mathrm{O}_{40}$ & POM-hybrid (1) & References \\
\hline Mo-O-Mo & - & 744 & 754 & {$[35]$} \\
$\mathrm{Si}-\mathrm{O}$ & - & 896 & 898 & {$[36]$} \\
Mo-O & - & 966 & 1004 & {$[35]$} \\
$\mathrm{C}-\mathrm{N}$ & 1453 & - & 1411 & {$[36]$} \\
$\mathrm{C}=\mathrm{O}$ & 1672 & - & 1607 & {$[37]$} \\
$\mathrm{N}-\mathrm{H}$ & 3424 & - & 3398 & {$[38]$} \\
\hline
\end{tabular}

plane is (010), (332), (152) and (253)] and $7.35^{\circ}, 8.27^{\circ}$ and $15.54^{\circ}$ [corresponding $\mathrm{hkl}$ plane of (001), (111) and (221)] which are presented in Fig. 2 b, c respectively. $[40,41]$. The appearance of a mixture of 2 theta peaks in composite 1 at $7.74^{\circ}$ and $12.66^{\circ}$ due to the presence of $\mathrm{H}_{4} \mathrm{SiMo}_{12} \mathrm{O}_{40}$, $25.58^{\circ}$ and $33.43^{\circ}$ arose from urea and $60.91^{\circ}$ emerged out from $\mathrm{Cu}\left(\mathrm{NO}_{3}\right)_{2} \cdot 3 \mathrm{H}_{2} \mathrm{O}$ confirms the presence of all individual components in composite $\mathbf{1}$ (Fig. 2d). The appearance of peaks in POM-hybrid (1) confirms composite exist in the crystalline phase.

\subsection{SEM - EDX spectroscopy}

To evaluate the surface analysis of prepared heterogeneous catalyst 1, SEM analysis was executed. The formed

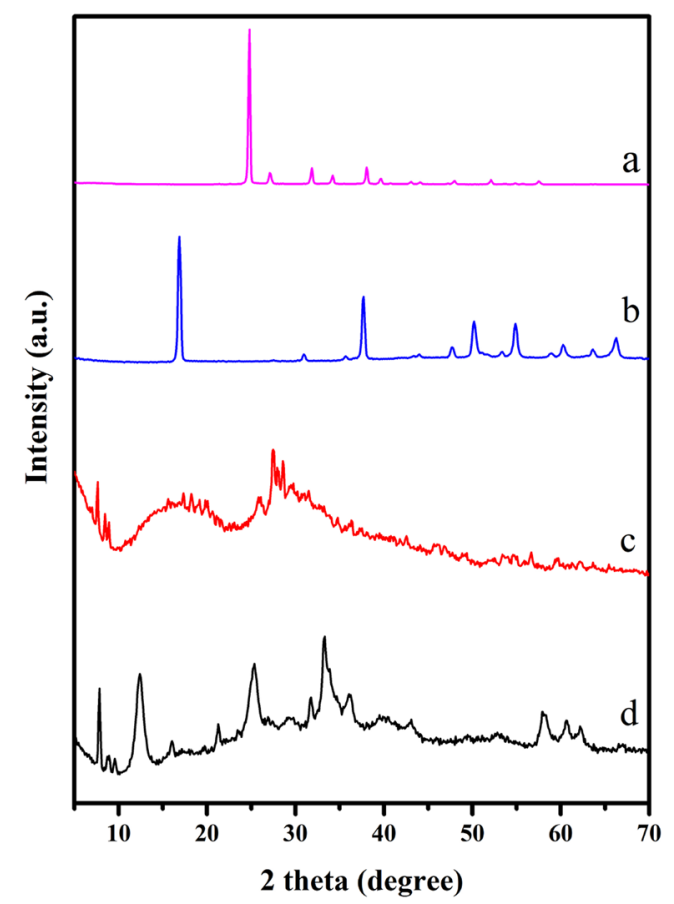

Fig. 2 PXRD pattern of a urea, b $\mathrm{Cu}\left(\mathrm{NO}_{3}\right)_{2} \cdot 3 \mathrm{H}_{2} \mathrm{O}, \mathbf{c} \mathrm{H}_{4} \mathrm{SiMo}_{12} \mathrm{O}_{40}$, d POM-hybrid (1) 
composite material was dipped in water for $1 \mathrm{~h}$ at room temperature without any disturbance and then filtered and dried. The SEM analysis was carried out in $97 \mathrm{~K} \times$ magnification whereby POM-hybrid (1) was analyzed as homogenously dispersed throughout the composite. The surface morphology of POM-hybrid (1) was found as a clear flake shaped structure. The resulting image of SEM micrographs of $\mathbf{1}$ catalyst is shown in Fig. 3a. The elemental composition of title compound $\mathbf{1}$ such as Carbon, Nitrogen, Oxygen, Copper, Silicon, and Molybdenum was examined by the SEM-EDX technique. The elemental composition of composite 1 was calculated from the EDX spectrum as shown in Fig. $3 \mathrm{~b}$ and corresponding elemental mapping analysis of each element have been provided in Fig. 4. The presence of nitrogen in the EDX spectrum of compound 1 confirms the existence of urea in the composite. It further confers the successful isolation of solid composite 1 .

\subsection{XPS analysis}

The chemical composition and elemental oxidation status of composite 1 were analyzed by recording X-ray photoelectron spectroscopy (XPS). The photoelectron peaks of elements $\mathrm{C}, \mathrm{N}, \mathrm{O}, \mathrm{Si}, \mathrm{Cu}$ and Mo have appeared at binding energies of 284.78 (C 1s), 398.08 (N 1s), 531.38 (O 1s), 102.08 (Si 2p), 934.98, 954.98 (Cu 2p) and 232.28, 235.38 (Mo 3d) eV respectively. High-resolution X-ray photoelectron spectra of composite 1 have been shown in Fig. 5. The measured binding energies of $\mathrm{Cu} 2 \mathrm{p}_{3 / 2}(934.98 \mathrm{eV})$ and $\mathrm{Cu}$ $2 \mathrm{p}_{1 / 2}(954.98 \mathrm{eV})$ confirms the existing nature of $\mathrm{Cu}$ as $\mathrm{Cu}^{2+}$ state in 1, which are consistent with the literature $[42,43]$. Besides, the appearance of two satellite peaks at 943.88 and $962.88 \mathrm{eV}$ further confirms the paramagnetic nature of $\mathrm{Cu}^{2+}$ ion. Binding energy observed at 232.28 and $235.38 \mathrm{eV}$ due to $\mathrm{Mo}^{6+} 3 \mathrm{~d}_{5 / 2}$ and $\mathrm{Mo}^{6+} 3 \mathrm{~d}_{3 / 2}$ orbitals which are strictly adhering with similar literature $[44,45]$. No traces of $\mathrm{Mo}^{+5}$ found and hence the result confirms that Mo atoms in compound 1 exist in its highest oxidation state +6 .

\subsection{BET analysis}

To explicate the surface behavior of catalyst 1, we have examined BET analysis of the title compound by using $\mathrm{N}_{2}$ sorption at $77.35 \mathrm{~K}$ [46]. The $\mathrm{N}_{2}$ adsorption-desorption isotherm of the synthesized POM-hybrid (1) catalyst is shown in Fig. 6a. The hysteresis observed which is correlated to the typical H3 (H3 is corrected) isothermal curve of mesopores (type IV) at $\mathrm{P} / \mathrm{Po}=0.80$. The calculated specific surface area of the title compound is $172.98 \mathrm{~m}^{2} \mathrm{~g}^{-1}$ which was significantly higher than the value found in the literature $[47,48]$. The pore size distribution by Barrett-Joyner-Halenda (BJH) analysis showed that the pore diameter of POM-hybrid (1) which was in the range of mesoporous (12.7-25.1 $\AA$ ) with a pore volume of $0.39 \mathrm{~cm}^{3}$. The maximum probability for feature size distribution is $\sim 14 \AA$ in diameter which is shown in Fig. 6b.

\subsection{UV-DRS analysis}

The tauc's plot was plotted $(\mathrm{ah} v)^{2}(\mathrm{eV})^{2} \mathrm{Vs}$ energy $(\mathrm{E})$, and the optical gap was calculated in ca. $2.06 \mathrm{eV}$. Bandgap value indicates that composite 1 can be used as semiconductor materials and a graph representing bandgap analysis has been shown in Fig. 7 [49]. Because of the interest of characterizing bandgap of composite 1, diffuse reflectance data has been analyzed. However, the application study of semiconductor might be irrelevant to the present work concern that will be dealt with separately.

The UV-DRS data was converted to the UV-Visible range using Kubelka-Munk Eq. 1.

$$
\mathrm{R}_{\mathrm{o}}=\frac{\exp \left\{\left(\frac{1}{\mathrm{R}_{\infty}}-\mathrm{R}_{\infty}\right) s \mathrm{~W}_{\text {std }}\right\}-1}{\frac{1}{\mathrm{R}_{\infty}} \exp \left\{\left(\frac{1}{\mathrm{R}_{\infty}}-\mathrm{R}_{\infty}\right) s \mathrm{~W}_{\text {std }}\right\}-\frac{1}{\mathrm{R}_{\infty}}}
$$
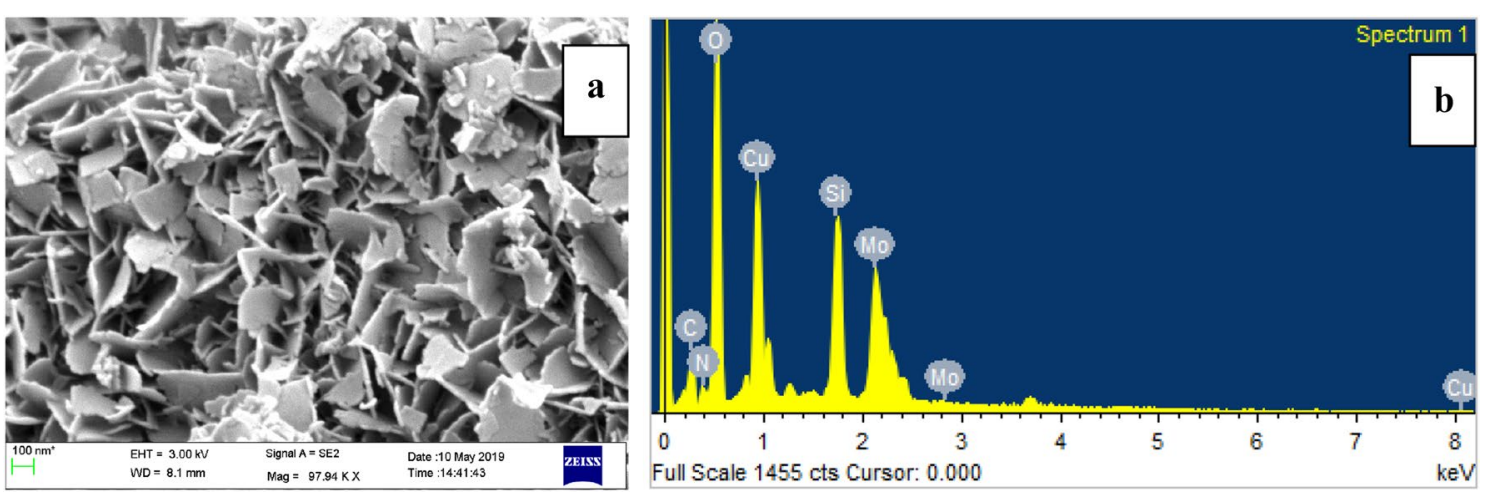

Fig. 3 a SEM micrographs of $\mathbf{1}$; $\mathbf{b}$ energy-dispersive X-ray spectrum of $\mathbf{1}$ 

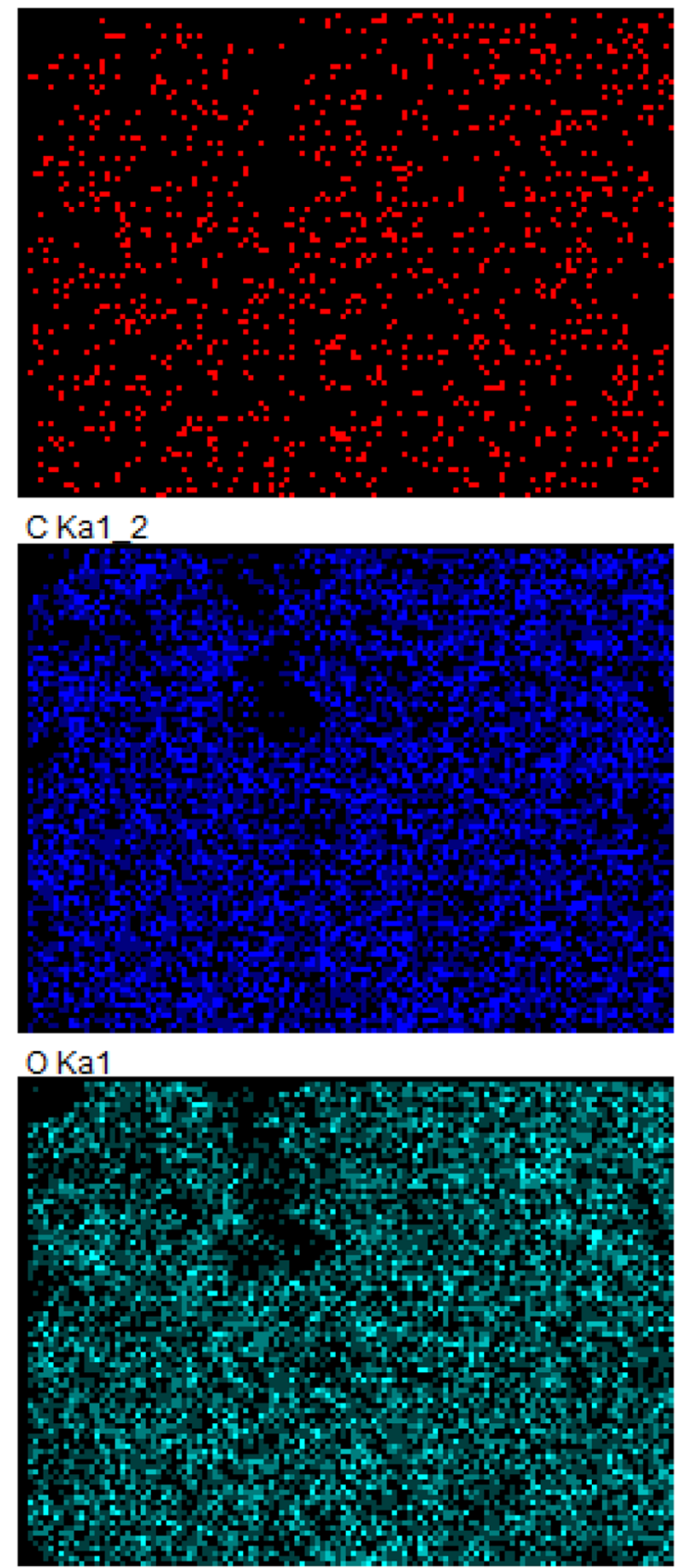

CuLa1_2

Fig. 4 Elemental composition mapping analysis of POM-hybrid 1

\subsection{Thermogravimetric and thermal degradation kinetics of POM-hybrid (1)}

Numerous analytical methods have been devised over the decades to estimate the kinetic parameters of solidstate reactions. There have been several methods being developed to calculate the kinetic parameters from the data acquired during isothermal solid-state transformation. Owing to the complexity and the time consumption
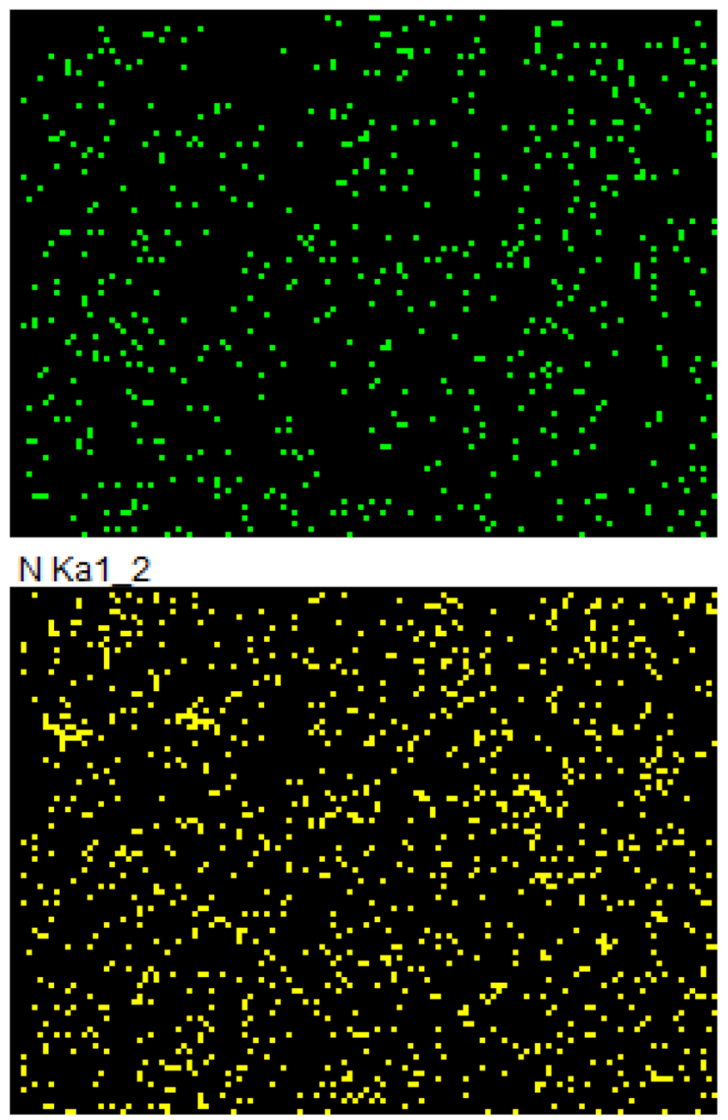

Si Ka1

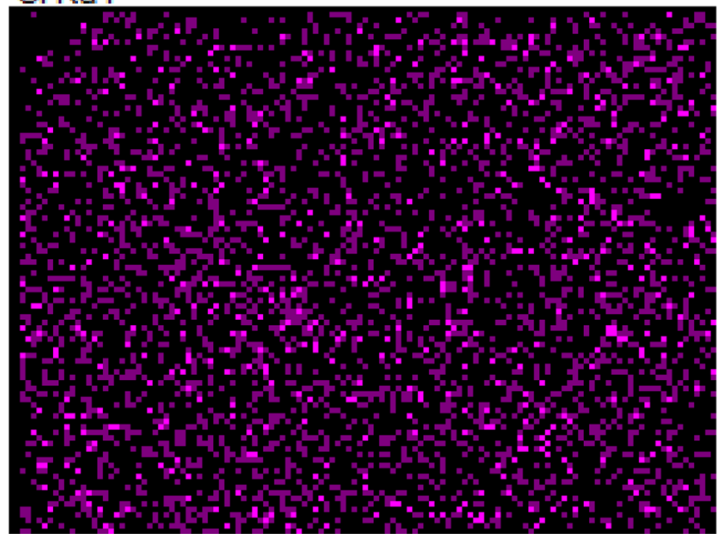

Mo La1

SN Applied Sciences

a SPRINGer Nature journal

in estimating the kinetic parameters under isothermal conditions, it is highly recommended to estimate the kinetic parameters from nonisothermal conditions $[50,51]$ using data obtained from different heating rates.

The most commonly used integral methods for the calculation of activation energies for the thermal degradation process of materials are Flynn-Wall-Ozawa (FWO) [52], Kissinger-Akahira-Sunose (KAS) [53] and Vyazovkin (VYZ) $[54,55]$ methods. To reduce the errors in calculation 

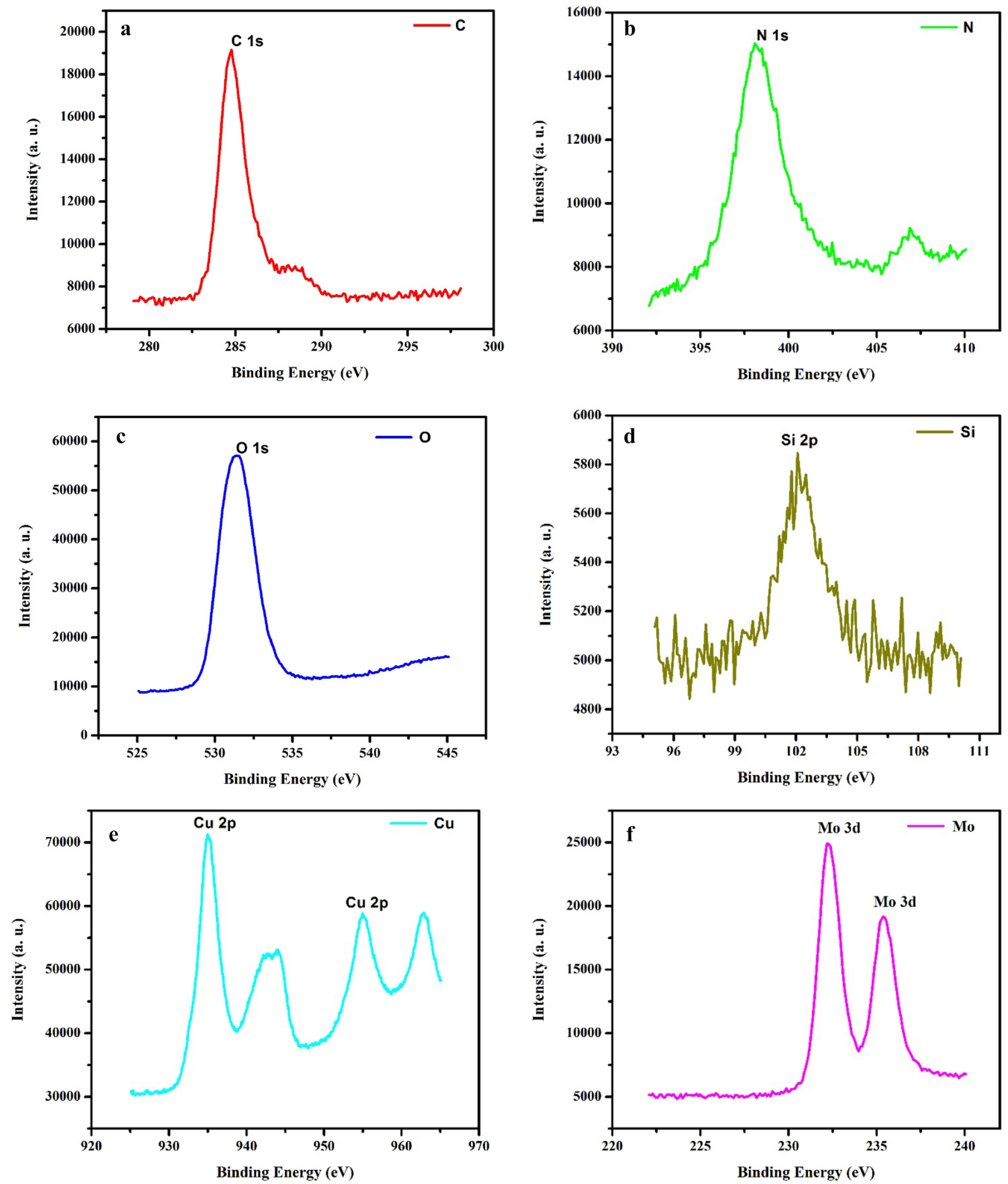

Fig. 5 High-resolution XPS spectra of POM-hybrid $\mathbf{1}$ a C, b N, c O, d Si, e Cu and f Mo 

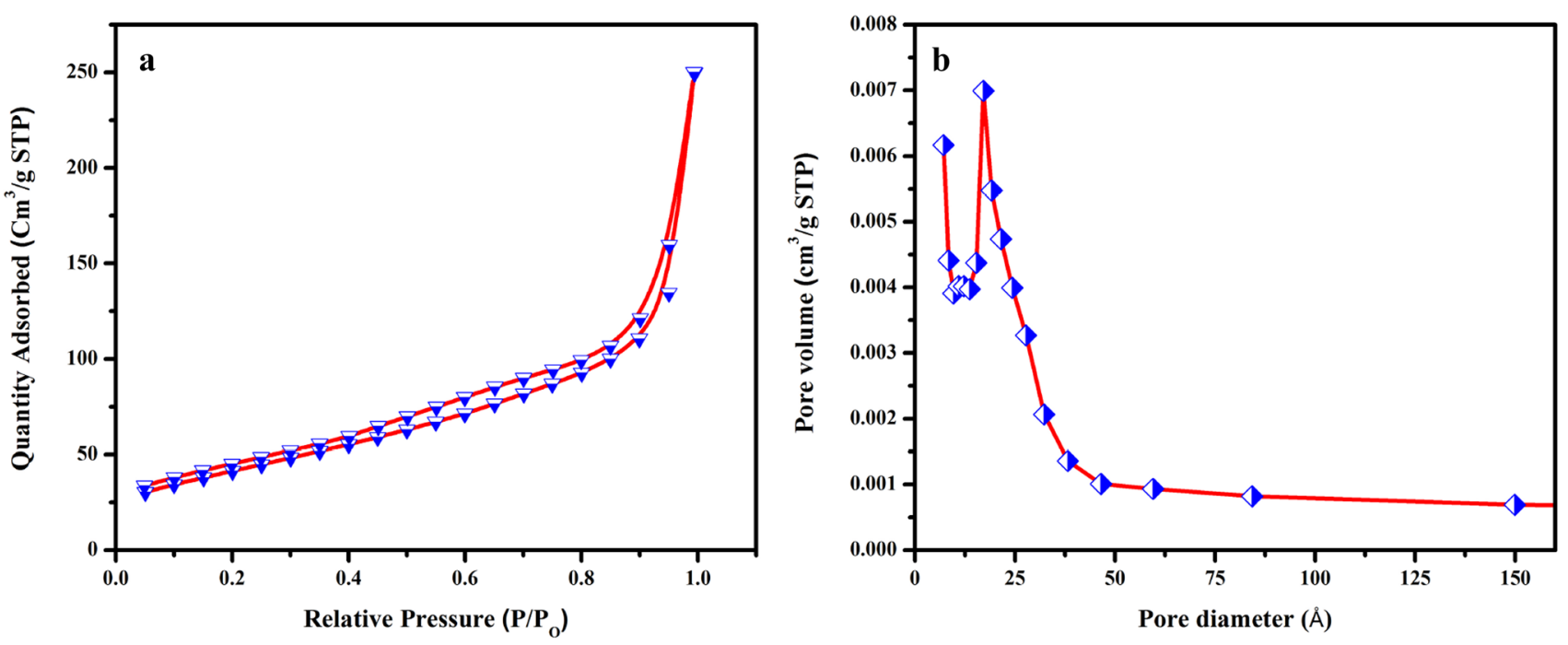

Fig. 6 BET analysis of POM-hybrid (1) a $\mathrm{N}_{2}$ adsorption-desorption isotherm curve; b Barrett-Joyner-Halenda (BJH) isotherm curve

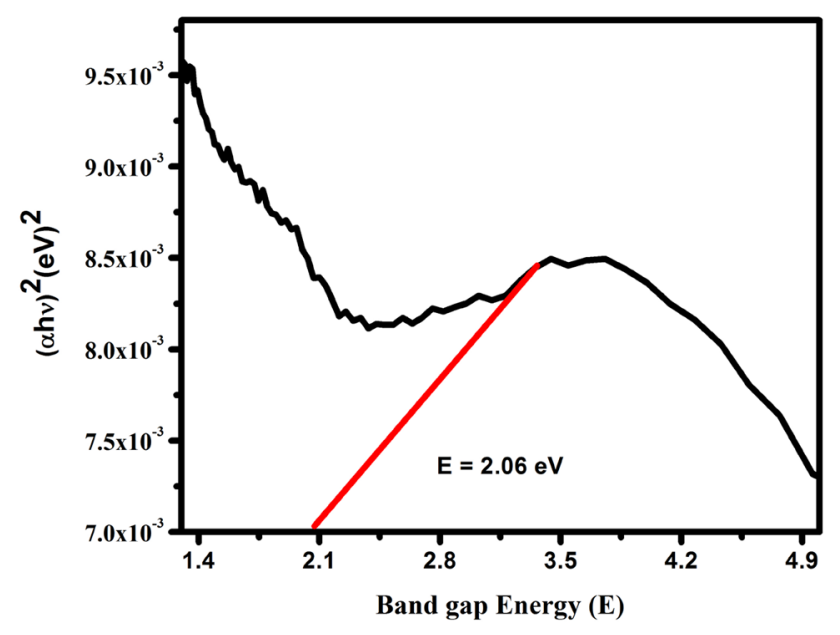

Fig. 7 Tauc's plot of POM-hybid (1)

Farjas [56] introduced an iteration process and corrected both FWO and KAS methods. Likewise, Vyazovkin made corrections for his procedure and gave the Advanced Vyazovkin (A-VYZ) procedure for calculating kinetic parameters [57]. Friedman (FRD) method [58] utilizes a differential approach to calculate the activation energy for thermal degradation by using TGA curves recorded at different heating rates.

The $E_{a}$ values calculated by the three methods (FWO, KAS, and VYZ) agreed very well, and the trends in the variation of $E_{a}$ for the curing of the bismaleimide and its blend with cloisite 15A nanoclay were nearly the same [59].

Detailed thermal degradation studies were carried out by Sarannya et al. [60] for thermally cured bisisomaleimide and cured blends of bisisomaleimide with different amounts of ortho novalac. The apparent activation energy for the thermal degradation of these thermally cured materials was calculated using four isoconversional model-free kinetic methods, such as FRD, Corrected FWO (C-FWO), Corrected KAS (C-KAS) and A-VYZ. Although the apparent activation energy values calculated for the degradation of cured samples by these methods are slightly different, the trends noted in the variation of apparent activation energy by the four kinetic methods are the same and the values are in good agreement.

Shamim Rishwana et al. [61] and Dhanalakshmi et al. [62] were also studied the thermal degradation kinetics of structurally different benzoxazines based on diphenols and diamines and structurally diverse poly(bispropargyl ethers-bismaleimide) blends respectively. The results of all methods are nearly the same. The slight deviation noted in the apparent activation energy values between these methods is due to the different approximations used in the kinetic methods.

Therefore in the present investigation, the authors used TG curves recorded at different heating rates for the calculation of apparent activation energy for the thermal degradation of POM-hybrid (1). Both the FWO and C-FWO methods were used in the present study.

The Thermogravimetric curves recorded for the sample POM-hybrid (1) at different heating rates $(\beta=10,15,20$ and $25^{\circ} \mathrm{C} \mathrm{min}{ }^{-1}$ ) are presented in Fig. 8. The degradation parameters derived from the TG curves are presented in Table 2. As the heating rate increases, the thermogravimetric curves are shifted to higher temperatures. The char (\%) value at $800^{\circ} \mathrm{C}$ amounts to an average of $74.6 \%$. From the recorded TG and DTG curves, the apparent activation energy (Ea-D) for the thermal degradation of POM-hybrid 


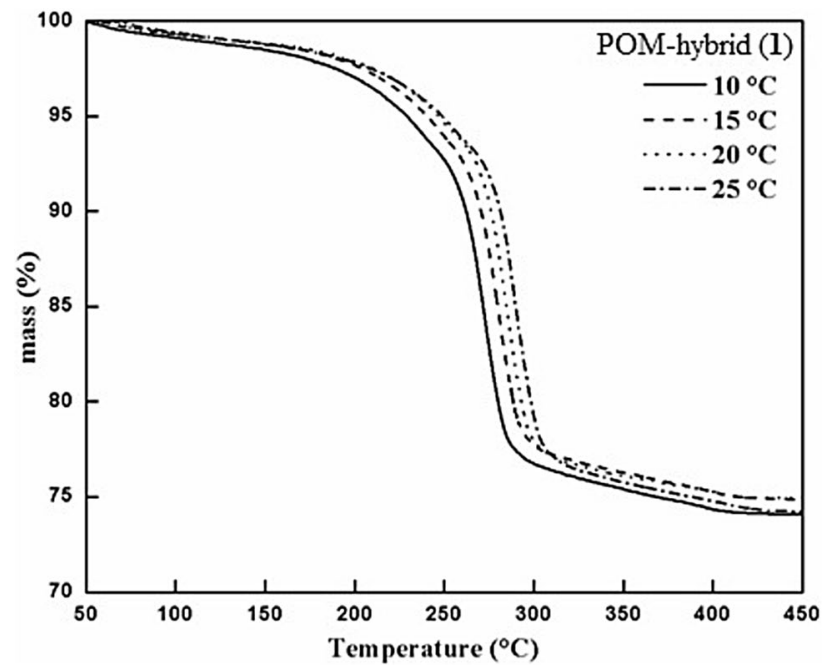

Fig. 8 TG curve of POM-hybrid (1) at different heating rates $(\beta=10$, 15,20 and $25^{\circ} \mathrm{C} \mathrm{min}^{-1}$ )

Table 2 Degradation parameters for POM-hybrid (1) at different heating rates $\left(\beta=10,15,20\right.$ and $\left.25^{\circ} \mathrm{C} \mathrm{min}^{-1}\right)$

\begin{tabular}{lllll}
\hline Sample code & $\beta\left({ }^{\circ} \mathrm{C} \mathrm{m^{-1 } )}\right.$ & $\begin{array}{l}\text { Temperature } \\
\left({ }^{\circ} \mathrm{C}\right)\end{array}$ & $\begin{array}{l}\text { Char residue } \\
(\%) \text { at } 800{ }^{\circ} \mathrm{C}\end{array}$ \\
\cline { 2 - 4 } & & $\mathrm{T}_{\mathrm{S}}$ & $\mathrm{T}_{\mathrm{E}}$ & \\
\hline POM-hybrid (1) & 10 & 150 & 275 & 73.7 \\
& 15 & 170 & 290 & 74.6 \\
& 20 & 180 & 300 & 75.8 \\
& 25 & 200 & 310 & 74.3 \\
\hline
\end{tabular}

$\mathrm{T}_{\mathrm{S}}$-starting temperature, $\mathrm{T}_{\mathrm{E}}$-ending temperature, $\mathrm{T}_{\max }-$ maximum degradation temperature

(1) for different reaction extents ( $\alpha=0.2$ to 0.8 ) were calculated using both the Flynn-Wall-Ozawa (FWO) and Corrected Flynn-Wall-Ozawa (C_FWO) model-free kinetic approximations. The basic equations involved in these methods are presented below.

\subsubsection{Flynn-Wall-Ozawa (FWO) method}

Flynn estimates the activation energy through different heating rates from the reciprocal of temperature.

$\ln \beta_{i}=\ln \left(\frac{A E}{R g(x)}\right)-1.0518 \frac{E}{R T_{i}}-5.330$

$\beta_{\mathrm{i}}$ is the multiple heating rates $\left(\mathrm{K} \mathrm{min}^{-1}\right) ; A$ is the pre-exponential factor $\left(\mathrm{min}^{-1}\right) ; \mathrm{E}$ is the activation energy $\left(\mathrm{kJmol}^{-1}\right)$; $R$ is the gas constant $\left(\mathrm{J} \mathrm{mol}^{-1} \mathrm{~K}^{-1}\right) ; \mathrm{g}(\mathrm{x})$ is the integral form of rate equation; $T_{i}$ is the temperature $(K)$.

\subsubsection{Corrected Flynn-Wall-Ozawa (C-FWO) method}

$\ln \beta_{i}-\ln \xi_{\text {FWO }}=\ln \left(\frac{A E}{R g(x)}\right)-1.0518 \frac{E}{R T_{i}}-5.330$

where

$\xi_{F W O}=\mathrm{p}\left(\mathrm{x}_{\mathrm{i}}\right) / \mathrm{e}^{(-1.0518 \mathrm{x}-5.330)}$

$x_{i}=E / R \bar{T}$

The Ea-D values calculated for different a values are presented in SI-Table 1 and the data are plotted and presented in Fig. 9.

The material shows a progressive increase in the Ea-D values from the beginning to the end of the degradation and the value ranges from 104 to $139 \mathrm{~kJ} \mathrm{~mol}^{-1}$. The probable structure for the material is presented in Scheme 3. From the hypothetical structure of the material, it is obvious that the POM units are linked to $\mathrm{Cu}$ ions through oxygen atoms. The urea present in the system may form hydrogen bonding through the $\mathrm{NH}_{2}$ groups and keto carbonyl may be coordinated with the $\mathrm{Cu}$ ions. During thermal degradation, the surface decorated urea molecules can be removed comparatively with ease than the urea molecules trapped inside the framework by hydrogen bonding. So it is reasonable to expect higher activation energy for higher a values. It is found to be true in this particular case.

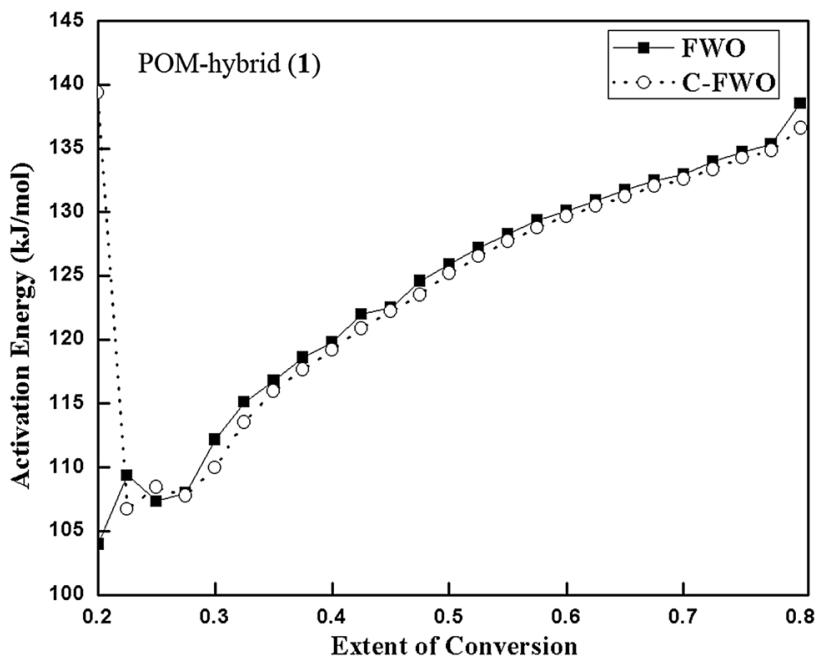

Fig. 9 The variation of apparent activation energy of thermal degradation of the sample POM-hybrid (1) at different a values 


\subsection{Reduction and kinetics}

The catalytic activity of title compound 1 under optimized conditions was investigated for the reduction of 2,4,6-TNP in the presence of $\mathrm{NaBH}_{4}$ (Fig. 10). The yellow solution of 2,4,6-TNP with an absorption peak at $354 \mathrm{~nm}$ was changed to red with an absorption maximum at $391 \mathrm{~nm}$ due to the adequate formation of phenolate ion. Moreover, 2,4,6-TNP ion was subsequently reduced into 2,4,6-TAP ion which shows maximum absorption at $304 \mathrm{~nm}$ (Scheme 1). The absorption peak at $391 \mathrm{~nm}$ was slowly decreased and a fresh peak appeared at $304 \mathrm{~nm}$. The progress of the reduction reaction was investigated with respect to concerning time. The complete conversion was noticed in a short period of $10 \mathrm{~min}$. It is worth mentioning that, the initial concentration of 2,4,6-TNP (100 ppm) employed in this study was significantly high when compared to the literature.

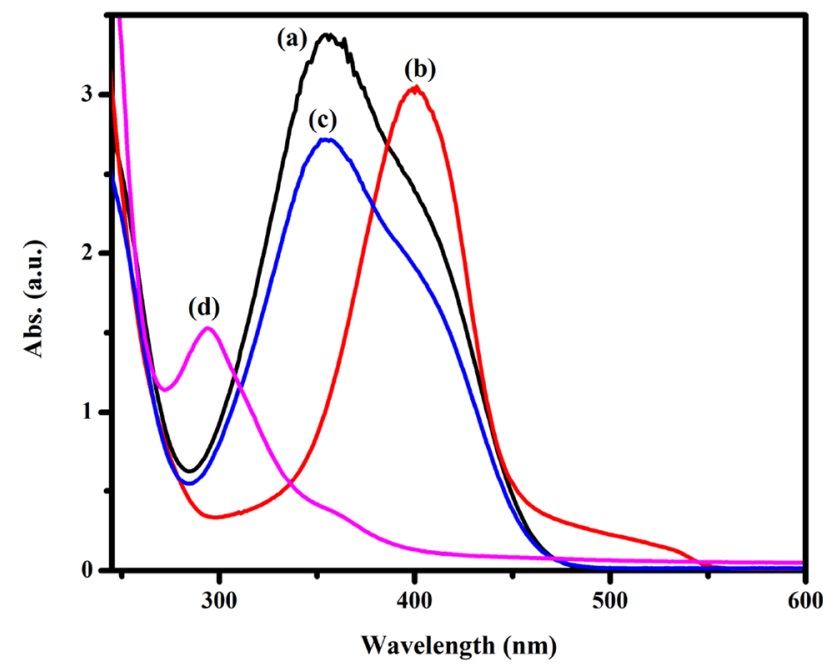

Fig. 10 UV-Visible spectra of a only 2,4,6-TNP; $\mathbf{b} 2,4,6-$ TNP in the presence of $\mathrm{NaBH}_{4}$ without catalyst; c 2,4,6-TNP in the presence of 1 without $\mathrm{NaBH}_{4}$; (d) 2,4,6-TNP in the presence of $\mathbf{1}$ and $\mathrm{NaBH}_{4}$
The rate of the reaction was determined by studying the absorbance at $391 \mathrm{~nm}$ (due to $-\mathrm{NO}_{2}$ chromophore group) as a function of time. The kinetic data fitted well and rate constant was calculated from the following Eq. 2 .

$\ln \left(C_{t} / C_{o}\right)=\ln \left(A_{t} / A_{o}\right)=-K_{a p p} t$

where $C_{o}$ and $C_{t}$ (or) $A_{o}$ and $A_{t}$ are initial concentration/ absorbance of 2,4,6-TNP (391 nm) and concentration at a time ' $t$ ' respectively; $K$ is rate constant and ' $t$ ' is time in second [63].

Since the solubility of both $2,4,6-\mathrm{TNP}\left(12.7 \mathrm{~g} / \mathrm{L} \mathrm{H}_{2} \mathrm{O}\right)$ and 4-NP $\left(15 \mathrm{~g} / \mathrm{L}\right.$ in $\left.\mathrm{H}_{2} \mathrm{O}\right)$ are more or less equal in aqueous solution it has been decided to extend the reductive hydrogenation to 4-NP also. Under the identical condition, 4-NP was loaded along with catalyst 1 and $\mathrm{NaBH}_{4}$ as aforementioned. Product formation of 4-AP was monitored and kinetics were also performed for the same. Furthermore, the concentration of $\mathrm{NaBH}_{4}$ was much higher in the present work with respect to NP derivatives and hence reductive hydrogenation in both the cases follows pseudo-first-order kinetics. The rate constant for 2,4,6-TNP is $4.85 \times 10^{-3} \mathrm{~s}^{-1}$ and the same for 4-NP is $5.38 \times 10^{-3} \mathrm{~s}^{-1}$. As the rate constant increases, the rate of conversion also increases. A moderately higher value of rate constants in present work, when compared to literature values, indicates that catalyst $\mathbf{1}$ has been efficient for the conversion. For better clarity of present work, a comparison of various catalysts and their catalytic ability for the same reduction reactions has been provided in Table 3, [64-71].

The results show both the reductions follow practically equal in their kinetics. However, initial fast reduction of 2,4,6-TNP in the first half of the time scale graph (Fig. 11) might be due to the formation of 2,4,6-trinitro phenolate ion intermediate which is more stabilized due to more number of $-\mathrm{NO}_{2}$ group. Due to the superior stability of 2,4,6-TNP ion compared to 4-NP ion, the rate of formation of former case increases and subsequently increases the reductive hydrogenation. However, the rate-determining step could be the slowest step where both 2,4,6-TNP and

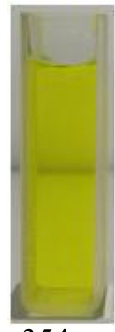<smiles>O=[N+]([O-])c1cc([N+](=O)[O-])c(O)c([N+](=O)[O-])c1</smiles>

$354 \mathrm{~nm}$
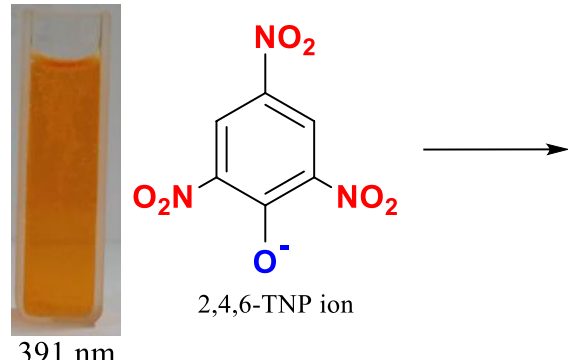

$391 \mathrm{~nm}$

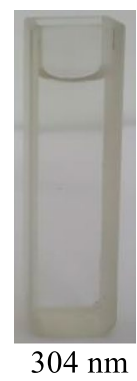<smiles>Nc1cc(N)c(O)c(N)c1</smiles>

2,4,6-TAP

Scheme 1 Pictorial representation of the conversion of 2,4,6-TNP into 2,4,6-TAP 
Table 3 Catalytic parameters for reduction of 2,4,6-TNP and 4-NP for reported catalysts

\begin{tabular}{lllll}
\hline Catalyst & Time $(\mathrm{min})$ & Recyclability & $\mathrm{K}_{\text {app }}$ & References \\
\hline 2,4,6-TNP & 5 & & & \\
AuNPs & 15 & Not studied & $6.41 \times 10^{-3} \mathrm{~s}^{-1}$ & {$[64]$} \\
AuNPs & 5 & $2.60 \times 10^{-3} \mathrm{~s}^{-1}$ & {$[65]$} \\
AgNP-PSAC & 20 & 10 & $234.40 \times 10^{-3} \mathrm{~s}^{-1}$ & {$[66]$} \\
Au@g-C3N4 & 10 & 10 & $1.01 \times 10^{-3} \mathrm{~s}^{-1}$ & {$[67]$} \\
POM-hybrid (1) & 10 & 10 & $4.85 \times 10^{-3} \mathrm{~s}^{-1}$ & This work \\
4-NP & & & & \\
PCN-224-700 (MOFs) & 10 & Not studied & $5.30 \times 10^{-3} \mathrm{~s}^{-1}$ & {$[68]$} \\
Ag-P2VP & 62 & 3 & $0.55 \times 10^{-3} \mathrm{~s}^{-1}$ & {$[69]$} \\
Au/Co3O4 & 10.7 & 5 & $5.00 \times 10^{-3} \mathrm{~s}^{-1}$ & {$[70]$} \\
Cu/C-800 hybrid & 12 & 7 & $24.00 \times 10^{-3} \mathrm{~s}^{-1}$ & {$[71]$} \\
POM-hybrid (1) & 10 & 10 & $5.38 \times 10^{-3} \mathrm{~s}^{-1}$ & This work \\
\hline
\end{tabular}

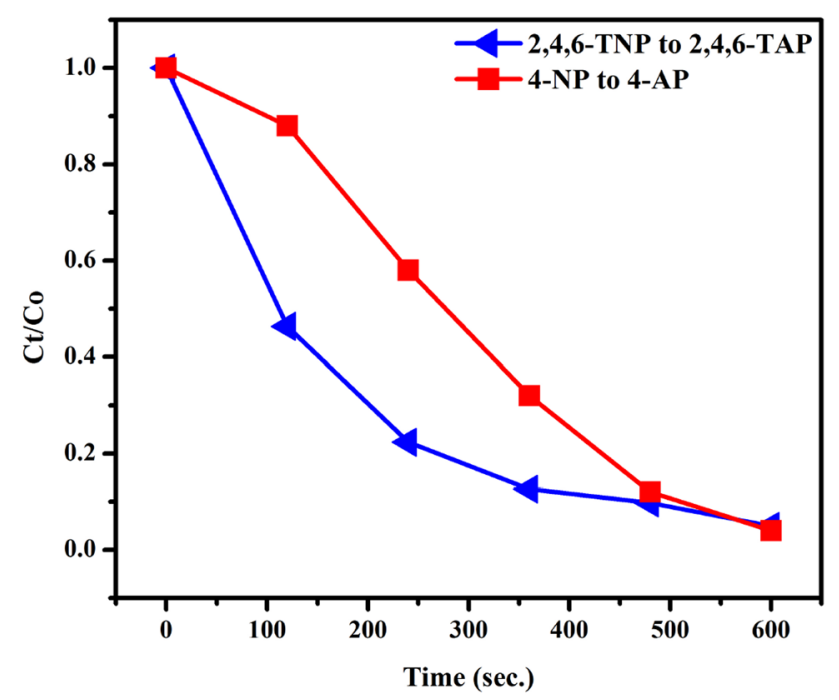

Fig. 11 Plot of $C_{t} / C_{o}$ versus reaction time for the reduction of a 2,4,6-TNP b 4-NP by using of POM-hybrid (1) with $\mathrm{NaBH}_{4}$

4-NP follow almost the same kinetics i.e. after 6 min rate of conversion is closer to identical. A graph showing pseudofirst-order kinetics is presented in Fig. 12.

Additionally, the formation of 2,4,6-TAP was confirmed by performing thin layer chromatography. As the reduction reaction proceeds the isolation of the appearance of colorless solid formation indicates the conversion of nitro to an amine. However, the solid has been isolated and recorded with ESI-mass spectrum $(\mathrm{m} / \mathrm{z}=142)$ which has been shown in SI-Fig. 1. As an additional support of evidence ${ }^{1} \mathrm{H}$-NMR (SI-Fig. 2 and 3) and FT-IR (SI-Fig. 4(a) and (4b)) spectra of 2,4,6-TNP and 2,4,6-TAP have been provided in supporting information.

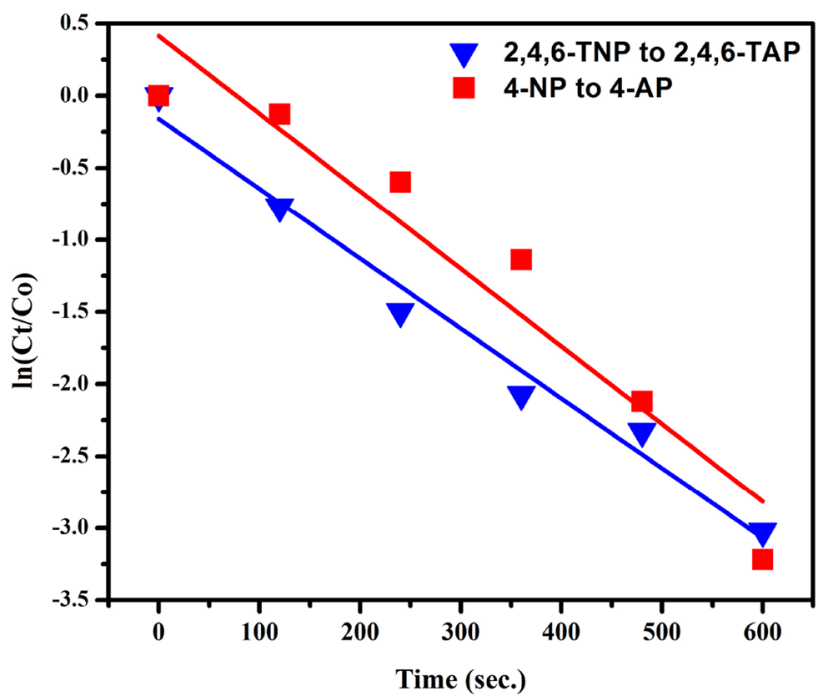

Fig. 12 Pseudo first order kinetic plot for the reduction of (a) 2,4,6TNP (b) 4-NP using POM-hybrid using $\mathrm{NaBH}_{4}$

UV-Graphs elucidating the aforementioned conversion of 2,4,6-TNP and 4-NP have been shown in Figs. 13 and 14 respectively. An enormous number of reports [65, 66] available for 4-NP reduction into 4-AP, however only very few of them dealt with $2,4,6-\operatorname{TNP}[72,73]$. The title compound discussed in this present work might be one of the rare examples of catalyst investigated for the reduction of 2,4,6-TNP into 2,4,6-TAP. Subsequently, the present work reporting the first example of the POM cluster being investigated as a reductive catalyst against 2,4,6-TNP in an aqueous solution. The reduction reaction was checked without the presence of $\mathrm{NaBH}_{4}$ and catalyst separately 


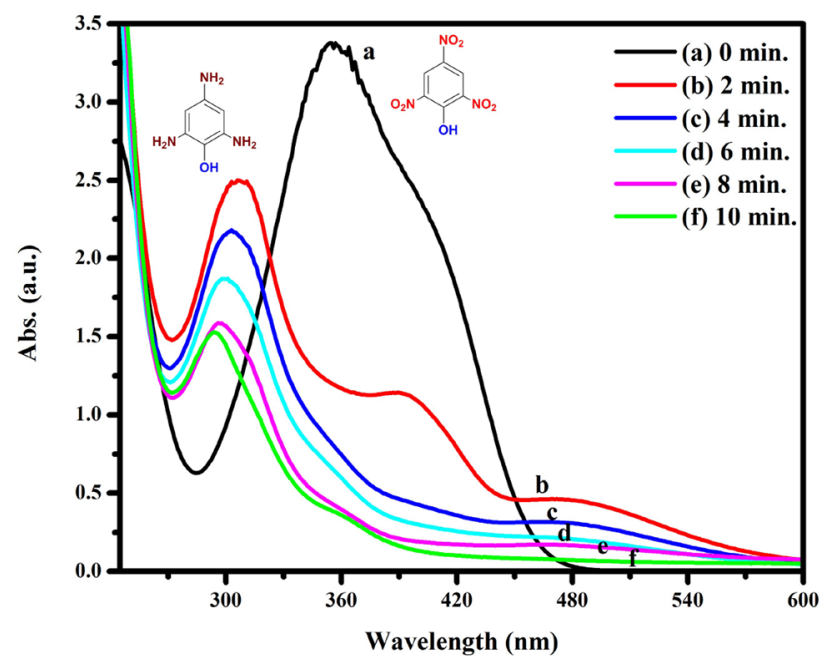

Fig. 13 Profile of UV-Visible spectroscopy of reduction 2,4,6-TNP by catalyst $\mathbf{1}$ in presence of $\mathrm{NaBH}_{4}$ with different time interval

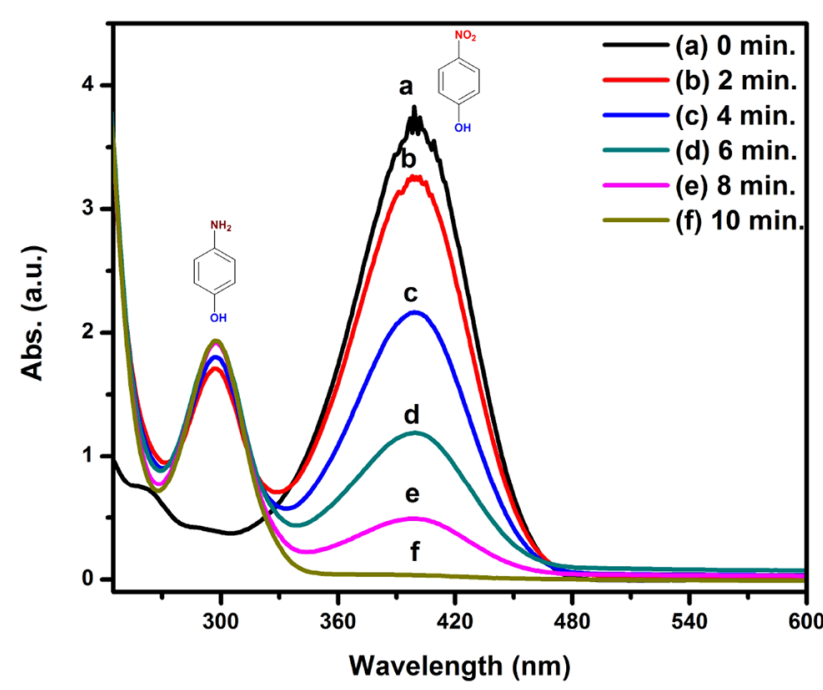

Fig. 14 Profile of reduction kinetics of 4-NP by catalyst 1 in presence of $\mathrm{NaBH}_{4}$ with different time interval

under identical conditions. The product 2,4,6-TAP does not form in either case which confirms the need for both $\mathrm{NaBH}_{4}$ and catalyst for successful conversion (Fig. 10). An attempt was made to prepare a catalyst of interest 1 , without the incidence of urea. Isolated colorless solid could not be able to reduce 2,4,6-TNP under the identical condition and hence which will not be discussed henceforth. It furnished an idea about the need for urea for the successful isolation of catalyst 1. It believed that urea act as bridging ligand between the POM framework and copper ion that affords a stable matrix which assists better adsorption of the substrate. The surface of copper ion has the potential to decompose $\mathrm{NaBH}_{4}$ and generate $\mathrm{H}_{2}$ gas which adsorb on POM framework and hence readily available for the reduction. It has been evidenced from literature that transition metal ions can be able to decompose $\mathrm{NaBH}_{4}$ [32]. Based on the above presumption the following mechanism of adsorption cum reduction mechanism was being proposed in Scheme 2.

Since the catalyst used here was heterogeneous we tried to enlighten the conversion of 2,4,6-TNP to 2,4,6-TAP in the presence of $\mathrm{NaBH}_{4}$ based on Langmuir-Hinshelwood adsorption mechanism (Scheme 2) [74]. Adsorption mechanism can be discussed in two steps. In step I, the adsorption of both 2,4,6-TNP and $\mathrm{NaBH}_{4}$ takes place over the surface of the catalyst. At step II hydrogen transferred from $\mathrm{BH}_{4}^{-}$ion to 2,4,6-TNP through the surface of the catalyst. It is well known that $\mathrm{BH}_{4}{ }^{-}$ion can be a good electron donor and $\mathrm{NO}_{2}$ as electron-withdrawing moiety while binding with the surface of a catalyst [65]. The XPS result indicates that no traces of reduced species such as $\mathrm{Cu}^{+}$and $\mathrm{Mo}^{+5}$ etc. were found in 1. It further support that electron transfer must be take place from $\mathrm{BH}_{4}{ }^{-}$ion (Fig. 5).

The rate of adsorption highly depends on the surface area of the catalyst which increases with increasing surface area. The notable surface area of the present catalyst (determined by BET) certainly helps for the successful adsorption and we believe it would be a key point for faster conversion. Additionally, $\pi-\pi$ stacking and in close proximity of planar geometry of 2,4,6-TNP assist in receiving electron to reduce itself to 2,4,6-TAP. Nevertheless, 2,4,6-TNP and 4-NP were analyzed with the same catalyst and Scheme 2 has been drawn by considering 2,4,6-TNP as representative.

Copper ion readily coordinated to both POM anion and urea. Subsequently, a complete matrix was stabilized by the hydrogen bonding network resulting in the formation of composite 1. A proposed schematic representation illustrating a structural network of title composite catalyst 1 has been shown in Scheme 3.

\subsection{Electrochemical reduction analysis by CV}

Electrocatalytic behavior of 1 was analyzed by cyclic voltammetry experiment against both 2,4,6-TNP and 4-NP. Cyclic voltammogram was recorded in the phosphate buffer solution where GCE, Ag wire and Pt wire were used as working, reference and counter electrode 
<smiles>O=[N+]([O-])c1cc([N+](=O)[O-])c(O)c([N+](=O)[O-])c1</smiles>

2,4,6-trinitrophenol $(2,4,6-T N P)$
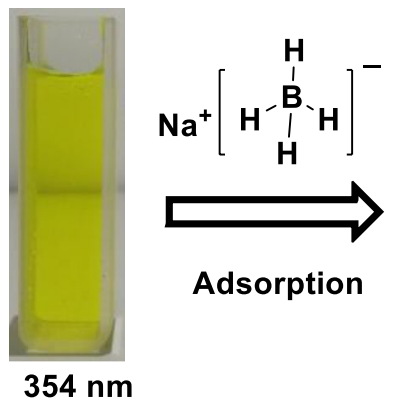

Adsorption

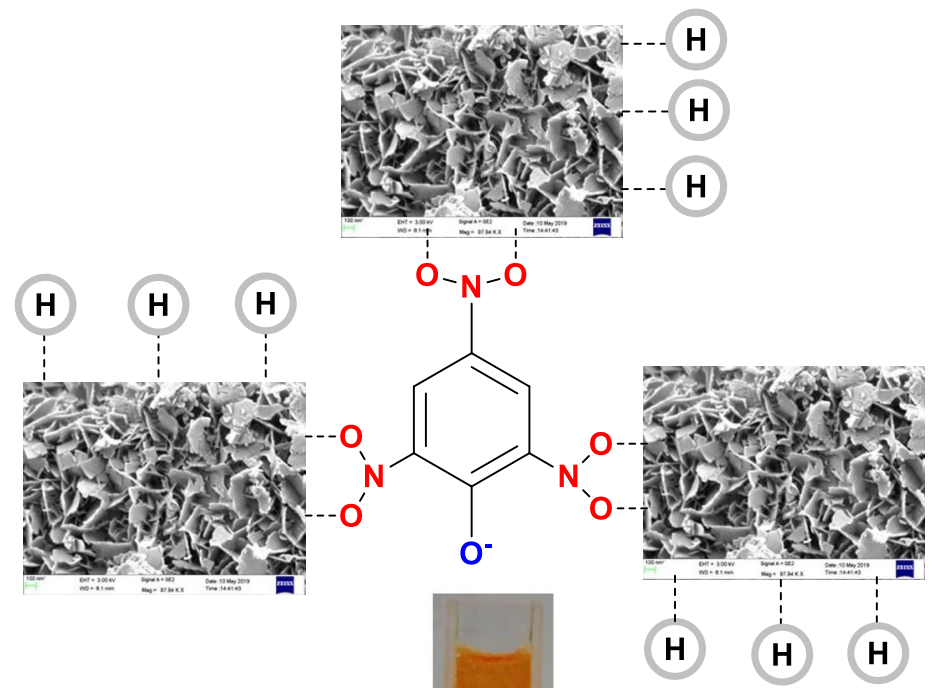<smiles>Nc1cc(N)c(O)c(N)c1</smiles>
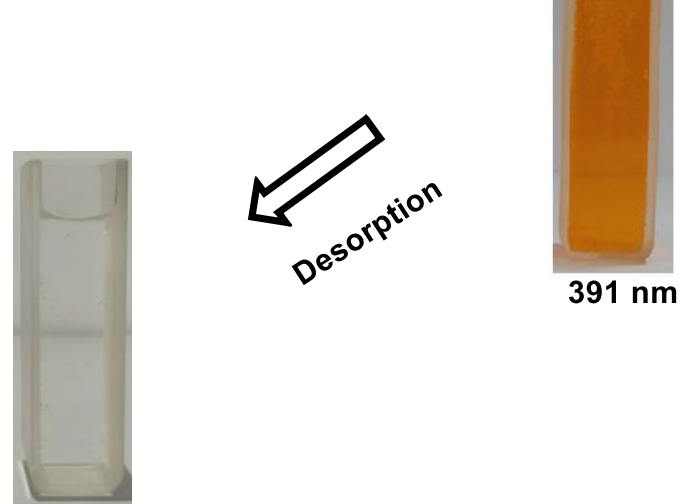

$304 \mathrm{~nm}$

Scheme 2 A Proposed mechanism for reduction of 2,4,6-TNP by $\mathrm{NaBH}_{4}$ over POM-hybrid (1) catalyst

respectively. The characteristic cyclic voltammogram was recorded within the range of $-1.30 \mathrm{~V}$ to $0.7 \mathrm{~V}$. Even though $\mathrm{CV}$ was recorded with various scan rates between 50 to $300 \mathrm{mV} \mathrm{s}^{-1}$, the scan rate $50 \mathrm{mV} \mathrm{s}^{-1}$ has been taken as representative for discussion. For better clarification electrochemical reductive catalysis experiments were carried out under identical conditions including the concentration of 2,4,6-TNP and 4-NP.

The Electrocatalysis of 2,4,6-TNP shows two oxidation peaks at $-0.12 \mathrm{~V},-0.75 \mathrm{~V}$ and only one reductive peak at $-0.25 \mathrm{~V}$. The negative reduction potential of both 4-NP and 2,4,6-TNP implies that the same reduction thermodynamically is not a feasible one. Electrocatalysis of 4-NP shows two oxidation peaks at $-0.05 \mathrm{~V}, 0.157 \mathrm{~V}$ and corresponding reductive potential observed at $-0.02 \mathrm{~V}$ and $-0.296 \mathrm{~V}$. Without the addition of $\mathrm{NaBH}_{4}$ electrocatalytic conversion was not successful. Cyclic voltammogram recorded at
$50 \mathrm{mV} \mathrm{s}^{-1}$ of both 2,4,6-TNP and 4-NP are shown in Fig. 15. Peak potential shifts concerning the scan rate of substrates 2,4,6-TNP and 4-NP are displayed in Fig. 16a, b respectively. Linear plots of cathodic reduction peak current against the square root of the scan rate were shown in Fig. 17a, $b$ respectively, which implies that the covalent binding nature of each component in composite 1.

\subsection{Reusability of catalyst}

Heterogeneous catalyst has the advantage of reusability over homogeneous catalysts. The catalyst used in the present study was filtered and washed with water and further investigated for ten cycles. Conversion time slowly increases as the number of cycles proceeded due to the reducing pore volume over the surface of the catalyst (Fig. 18). A good catalyst should not change 


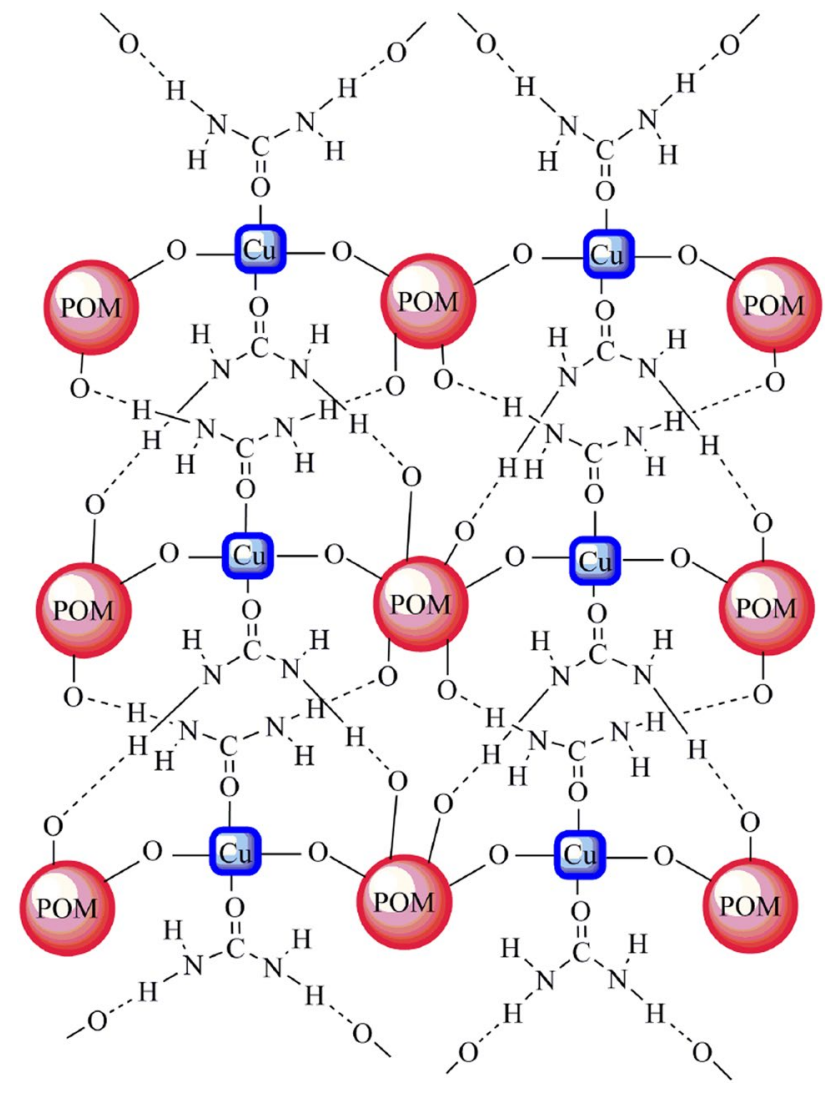

Scheme 3 Proposed structural network of POM-hybrid (1)

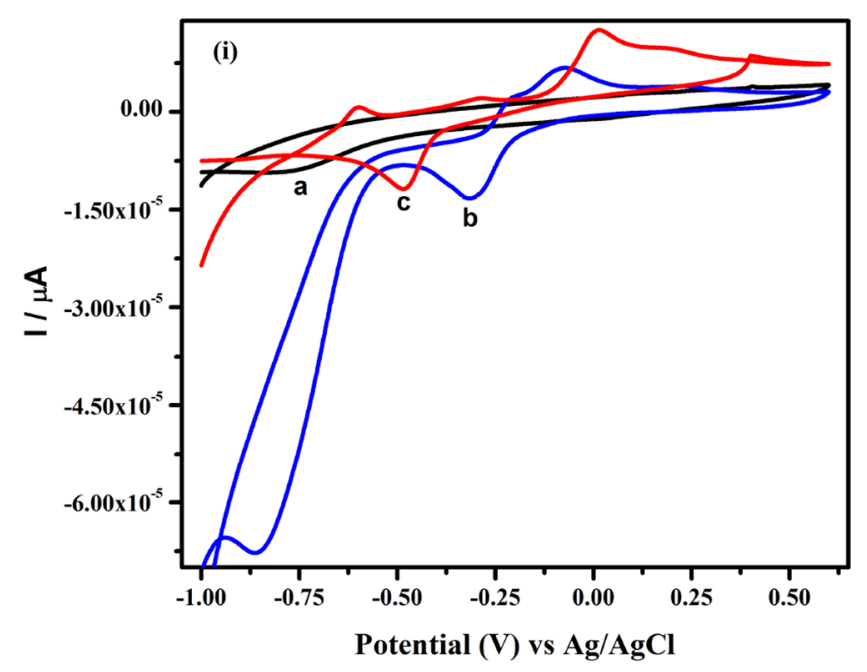

Fig. 15 Cyclic voltammogram of $\mathbf{i}$ (a) Bare GCE with PBS; (b) POMhybrid (1)/GCE with 2,4,6-TNP in PBS (pH 7) solution without $\mathrm{NaBH}_{4}$; (c) POM-hybrid (1)/GCE in PBS (pH 7) solution in the presence of its unique phase and composition during each cycle. To confirm the survival of catalyst after its tenth cycle, it was subjected to record FT-IR spectroscopy. The presence of similar peaks of first and tenth cycles was proved that survival of catalyst with the same phase and composition even after its subsequent usage ten times. For better clarity, the coincidence of the FT-IR spectra of the initial and final cycles has been shown in Fig. 19.

\subsection{Leaching test}

Strongly bounded elements in a composite material certainly will not be leached out of the framework which can be determined by leaching test. In a typical experiment, the catalyst (1) used in the present study was subjected to immersion distilled water for $72 \mathrm{~h}$. FT-IR spectra of both original and immersed catalyst showed identical peaks thereby confirming there was no either of component leached out insisting strong covalent interaction in the framework (Fig. 20).

\section{Conclusion}

In summary, we are reporting a novel methodology for the synthesis of inorganic hybrid composite material POM-hybrid (1). The resultant composite material $\mathbf{1}$ having flake structure and morphology was characterized by SEM analysis. Additionally, the material was characterized by FT-IR, PXRD, SEM, SEM-EDX techniques, UV-DRS and $X P S$. Thermal degradation kinetics insists that catalyst 1

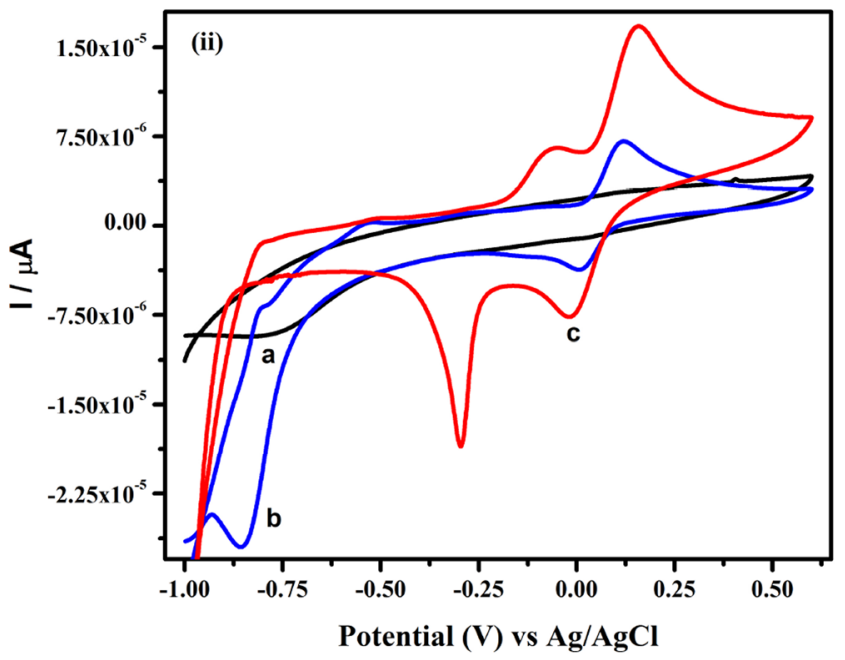

$\mathrm{NaBH}_{4}$; ii (a) Bare GCE with PBS; (b) POM-hybrid (1)/GCE with 4-NP in PBS (pH 7) solution without $\mathrm{NaBH}_{4}$; (c) POM-hybrid (1)/GCE in PBS (pH 7) solution in the presence of $\mathrm{NaBH}_{4}$ 

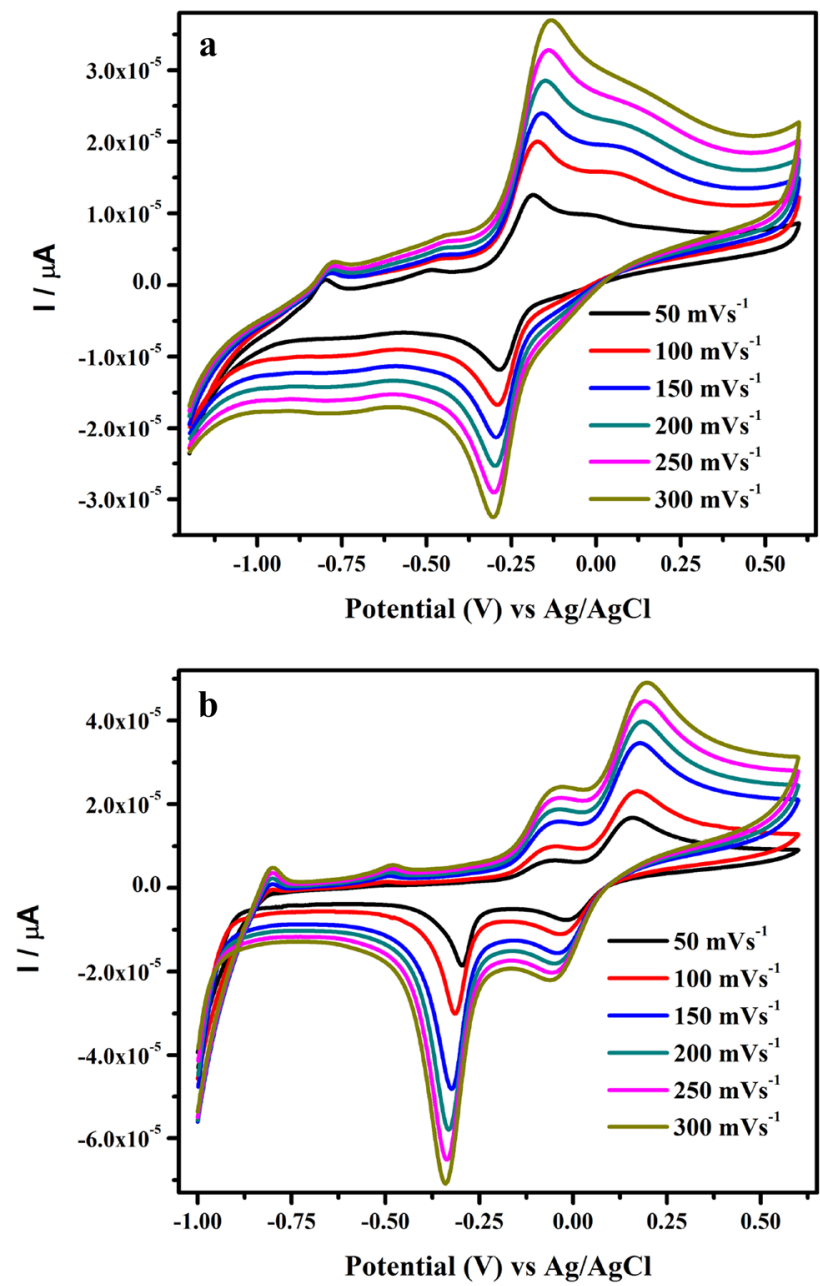

Fig. 16 a Reduction of 2,4,6-TNP at various scan rates in presence of POM-hybrid (1)/GCE. b Reduction of 4-NP at various scan rates in presence of POM-hybrid (1)/GCE

having activation energy in the range of $104-139 \mathrm{~kJ} \mathrm{~mol}^{-1}$ and stable up to $310^{\circ} \mathrm{C}$ temperature. Further, extending the application of composite $\mathbf{1}$ for the reduction of 2,4,6-TNP to 2,4,6-TAP and 4-NP to 4-AP was investigated in an aqueous medium. In this work, we report the synthesis and application of the first POM based composite hybrid catalyst identified as a reductive hydrogenation
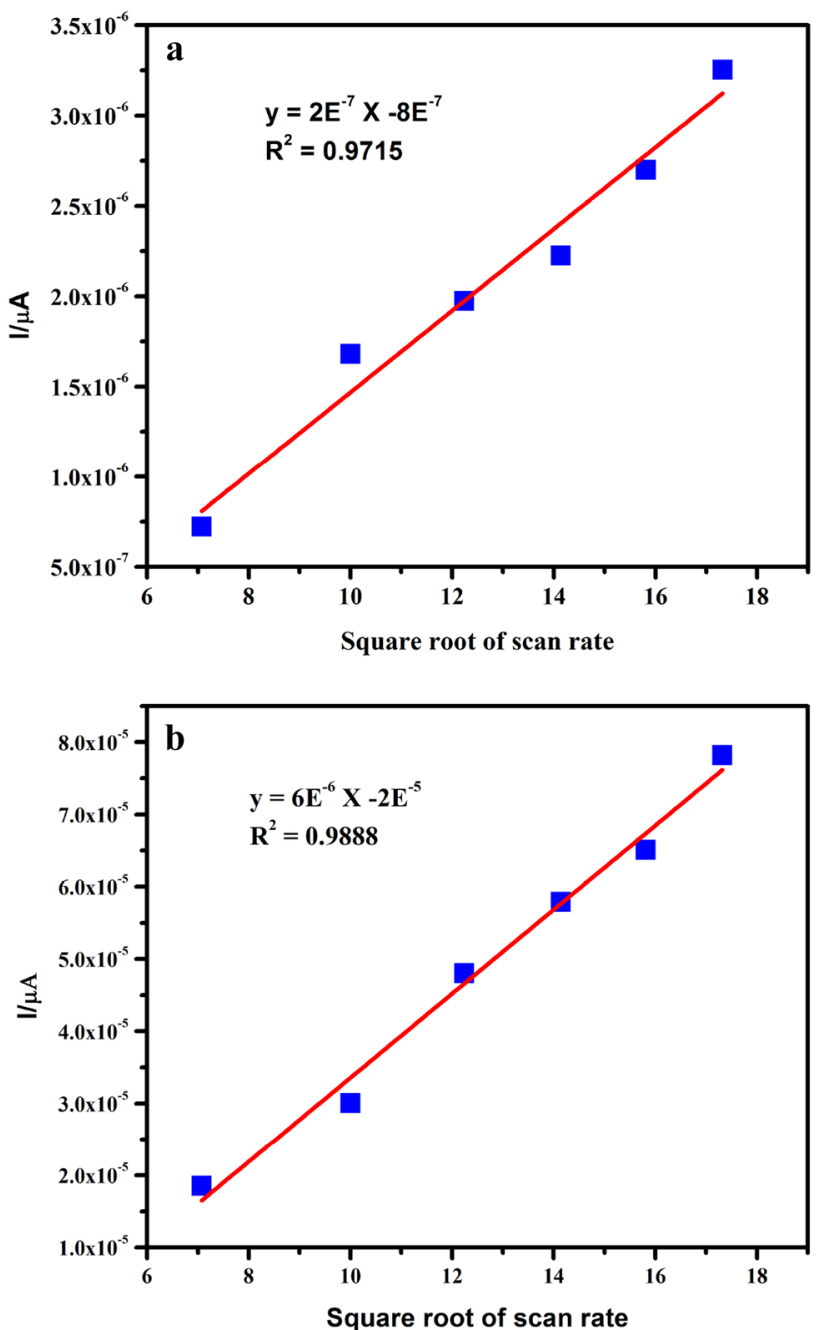

Fig. 17 A plot of anodic oxidation peak current against square root of scan rate of a POM-hybrid (1)/GCE for the reduction of 2,4,6-TNP. b POM-hybrid (1)/GCE for the reduction of 4-NP

catalyst for 2,4,6-TNP. Kinetic study of the reduction follows pseudo-first-order concerning the concentration of NP derivative. Complete conversion of nitro to amine takes place within a short period of $10 \mathrm{~min}$ and the transformation was monitored by UV-visible spectrophotometer. Moreover, product formation was confirmed by FT-IR, ${ }^{1} \mathrm{H}$ 

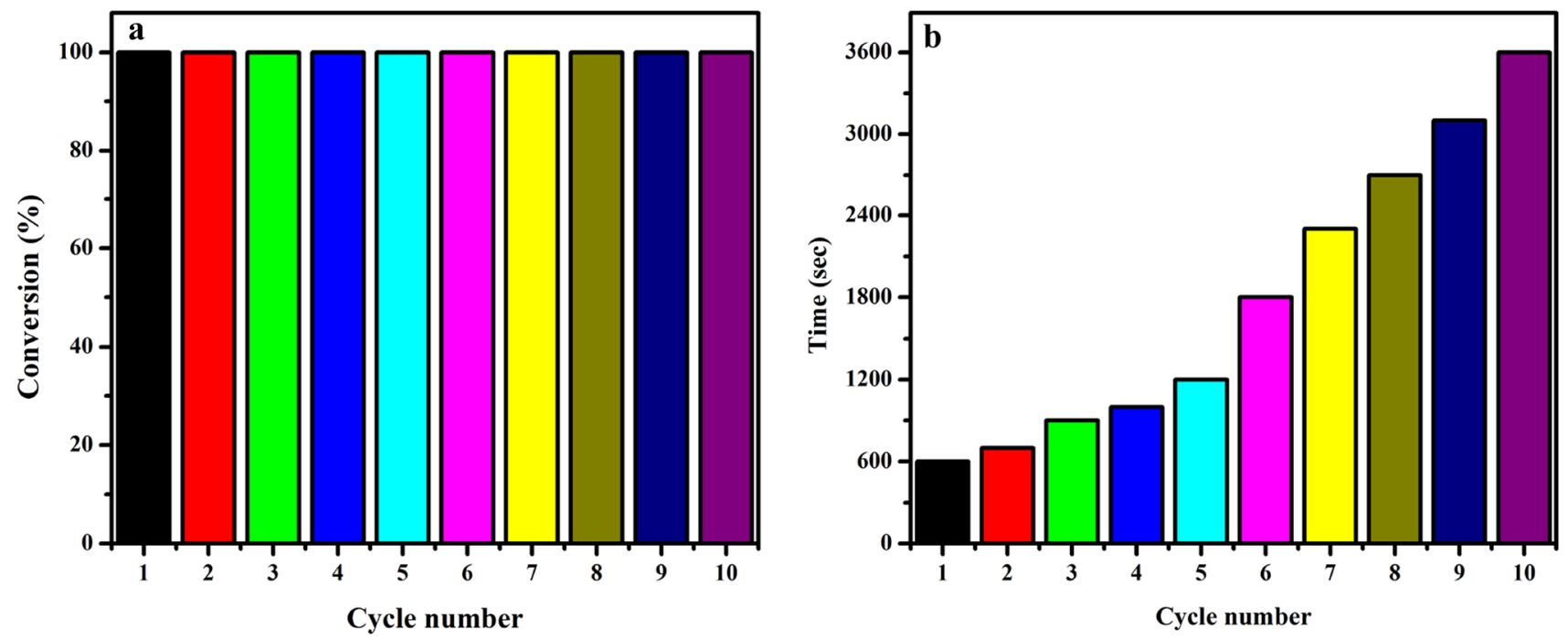

Fig. 18 a Bar graph showing catalytic profile of POM-hybrid (1) for the substrate 2,4,6-TNP at different cycles: a percentage of product conversion $\mathbf{b}$ time taken for different cycles

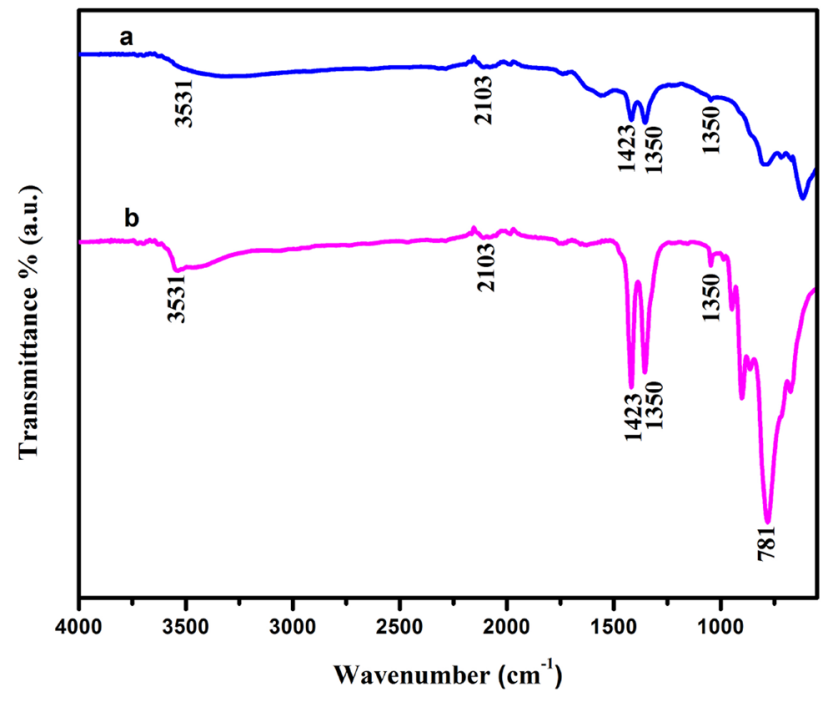

Fig. 19 IR spectrum of POM-hybrid (1); a after usage of 10th cycle; b before use

NMR and ESI-Mass. Recycling of catalyst 1 was studied at least for ten cycles. Reusability and leaching test was confirmed by FT-IR spectroscopy. Potential catalytic ability of $\mathbf{1}$ may open a new pathway in the field of organic pollutant removal from an aqueous medium by reductive hydrogenation and it is the need of an hour as for as environment concerned.

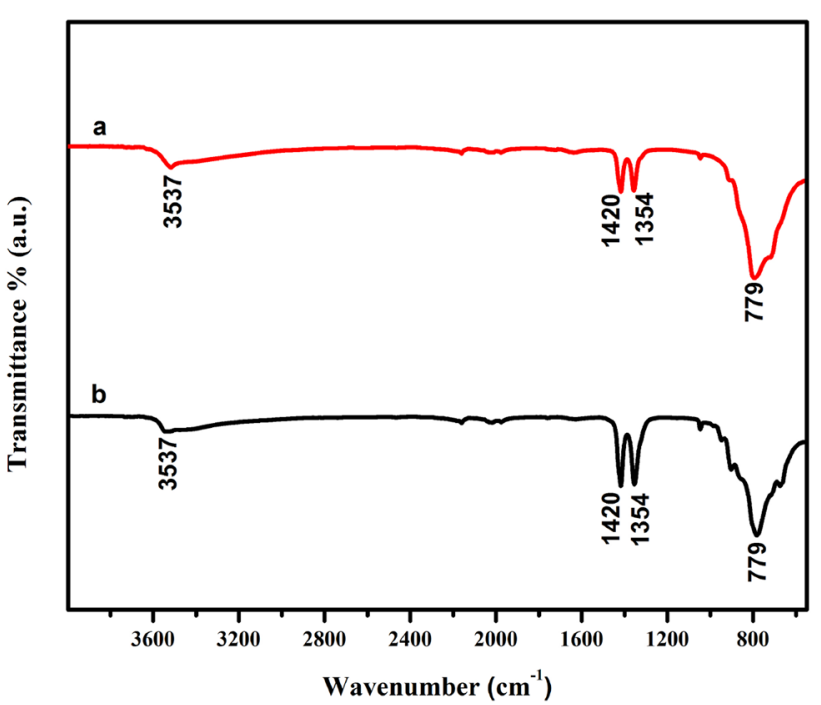

Fig. 20 FT-IR spectra of POM-hybrid (1): a after leaching; b before leaching

Acknowledgements The author Dr. Arumuganathan thank the Department of Science and Technology - Science and Engineering Research Board (DST - SERB) for the financial support by the fast track research Grant (SB/FT-CS- 061/2013). Mr. C. Sabarinathan thanks UGC-NRC, School of Chemistry, and The University of Hyderabad for providing internship fellowship and infrastructure facilities provided. Prof. Samar Kumar Das (Coordinator for UGC - NRC) and Prof. V. Baskar, School of Chemistry, University of Hyderabad gratefully acknowledged for mentoring C. Sabarinathan for the internship program. Support availed from Mr. Aravind, Assistant Professor of English, Thiagarajar College is gratefully acknowledged. The author thanks the Management, Thiagarajar College, Madurai -09 for providing infrastructure and support provided. 


\section{Compliance with ethical standards}

Conflict of interest The authors declare no conflict of interest.

\section{References}

1. Dixon DJ, Morejon OP (2014) Recent developments in the reduction of nitro and nitroso compounds. Compr Org Synth II 8:479-492

2. Kovac J (2001) The big bang: a history of explosives (Brown, G. I.). J Chem Educ 78:36

3. Feng ZV, Lyon JL, Croley JS, Crooks RM, Bout DAV, Stevenson KJ (2009) Synthesis and catalytic evaluation of dendrimer-encapsulated Cu nanoparticles an undergraduate experiment exploring catalytic nanomaterials. J Chem Educ 86:368-372

4. Chiou JR, Lai BH, Hsu KC, Chen DH (2013) One-pot green synthesis of silver/iron oxide composite nanoparticles for 4-nitrophenol reduction. J Hazard Mater 248:394-400

5. Pandey S, Mishra SB (2014) Catalytic reduction of p-nitrophenol by using platinum nanoparticles stabilized by guar gum. Carbohydr Polym 113:525-531

6. Bouazizi N, Vieillard J, Thebault P, Desirac F, Clamens T, Bargougui R, Couvrat N, Thoumire O, Brun N, Ladam G, Morin S, Mofaddel N, Lesouhaitier O, Azzouz A, Derf FL (2018) Silver nanoparticles embedded copper oxide as efficient core shell for catalytic reduction of 4-nitrophenol and antibacterial activity improvements. Dalton Trans 47:9143-9155

7. Abu Bakar NHH, Ridzwan A, Tan WL, Abu Bakar M, Sabri NA (2019) Facile preparation of porous silicon from cost-wise silicon powder as effective catalyst for reduction of $p$-nitrophenol. Mater Chem Phys 232:387-392

8. Dash S, Das S, Khan MI, Sinha S, Das B, Jayabalan R, Tripathy SK (2018) Sonochemically Synthesized $\mathrm{Ag} / \mathrm{CaCO}_{3}$ nanocomposites: a highly efficient reusable catalyst for reduction of 4-nitrophenol. Mater Chem Phys. https://doi.org/10.1016/j. matchemphys.2018.09.019

9. Kavita S, Jaspal S, Satyabrata M (2019) Catalytic reduction of 4-nitrophenol and photocatalytic degradation of organic pollutants in water by copper oxide nanosheets. Opt Mater 93:58-69

10. Quites FJ, Azevedo CKS, Alves EPP, Germino JC, Vinhas RCG, Landers R, Terezo AJ, Atvars TDZ (2017) Ag nanoparticles-based zinc hydroxide-layered hybrids as novel and efficient catalysts for reduction of 4-nitrophenol to 4-aminophenol. J Braz Chem Soc 28:106-115

11. Zarringhadam $\mathrm{P}$, Farhadi $\mathrm{S}$ (2017) Flower-like $\mathrm{Bi}_{2} \mathrm{O}_{2} \mathrm{CO}_{3} /$ $\mathrm{NiFe}_{2} \mathrm{O}_{4}$ magnetically recoverable nanocomposites: preparation, characterization and their catalytic application in the reduction of 4-nitrophenol to 4-aminophenol. J Alloys Compd 729:1046-1057

12. Yusran $Y, X u$ D, Fang Q, Zhang D, Qiu S (2016) MOF-derived Co@N-C nanocatalyst for catalytic reduction of 4-nitrophenol to 4-aminophenol. Micro Mesoporous Mater 241:346-354

13. Bano M, Ahirwar D, Thomas M, Naikoo GA, Sheikh MUD, Khan F (2016) Hierarchical synthesis of silver monoliths and their efficient catalytic activity for the reduction of 4-nitrophenol to 4-aminophenol. New J Chem 40:6787-6795

14. Bhosale MA, Chenna DR, Ahire JP, Bhanage BM (2015) Morphological study of microwave-assisted facile synthesis of gold nanoflowers/nanoparticles in aqueous medium and their catalytic application for reduction of $p$-nitrophenol to p-aminophenol. RSC Adv 5:52817-52823
15. Narayanan RK, Devaki SJ (2015) Brawny silver-hydrogel based nanocatalyst for reduction of nitrophenols: studies on kinetics and mechanism. Ind Eng Chem Res 54:1197-1203

16. Zhou A, Li J, Wang G, Xu Q (2019) Preparation of Ag/ZrGP nanocomposites with enhanced catalytic activity for catalytic reduction of 4-nitrophenol. Appl Surf Sci. https://doi. org/10.1016/j.apsusc.2019.144570

17. Gao $Y$, Zhang $Y$, Zhou $Y$, Zhang $C$, Zhang $H$, Zhao S, Fang J, Huang M, Sheng $X$ (2017) Synthesis of ordered mesoporous La2O3-ZrO2 composites with encapsulated Pt NPs and the effect of La-dopping on catalytic activity. J Colloid Interface Sci 503:178-185

18. Sogukomerogullari $H G$, Karatas $Y$, Celebi M, Gulcan $M$, Sonmez M, Zahmakiran M (2019) Palladium nanoparticles decorated on amine functionalized graphene nanosheets as excellent nanocatalyst for the hydrogenation of nitrophenols to aminophenol counterparts. J Hazard Mater. https://doi. org/10.1016/j.jhazmat.2019.02.027

19. Deka JR, Budi LC, Saikia D, Yang YC, Kao HM (2018) Carboxylic acid functionalized cage-type mesoporous silica FDU-12 as support for controlled synthesis of platinum nanoparticles and its catalytic applications. Chem Eur J. https://doi. org/10.1002/chem.201802146

20. Fu Y, Huang T, Jia B, Zhu J, Wang X (2017) Reduction of nitrophenols to aminophenols under concerted catalysis by $\mathrm{Au} / \mathrm{g}$ $\mathrm{C}_{3} \mathrm{~N}_{4}$ contact system. Appl Catal B Environ 202:430-437

21. Zhang J, Huang Y, Li G, Wei Y (2019) Recent advances in alkoxylation chemistry of polyoxometalates: from synthetic strategies, structural overviews to functional applications. Coord Chem Rev 378:395-414

22. Dui X, Yang W, Wu X, Kuang X, Liao J, Yu R, Lu C (2015) Two novel POM-based inorganic-organic hybrid compounds: synthesis, structures, magnetic properties, photodegradation and selective absorption of organic dyes. Dalton Trans 44:9496-9505

23. Reddy PG, Mamidi N, Pradeep CP (2016) An organic-inorganic hybrid supramolecular framework material based on a $\left[\mathrm{P}_{2} \mathrm{~W}_{18} \mathrm{O}_{62}\right]^{6-}$ cluster and $\mathrm{Yb}$ and $\mathrm{Na}$ complexes of pyridine2,6-dicarboxylic acid: a catalyst for selective oxidation of sulfides in water with $\mathrm{H}_{2} \mathrm{O}_{2}$. CrystEngComm 18:4272-4276

24. Sabarinathan $C$, Karuppasamy P, Vijayakumar CT, Arumuganathan T (2019) Development of methylene blue removal methodology by adsorption using molecular polyoxometalate: kinetics, thermodynamics and mechanistic study. Microchem J 146:315-326

25. Qu X, Feng H, Ma C, Yang Y, Yu X (2017) Synthesis, crystal structure and anti-tumor activity of a novel 3D supramolecular compound constructed from strandberg-type polyoxometalate and benzimidazole. Inorg Chem Commun 81:22-26

26. Sabarinathan C, Karthikeyan M, Harisma BR, Murugappan RM, Arumuganathan T (2019) One pot synthesis of luminescent polyoxometalate supported transition metal complex and biological evaluation as a potential larvicidal and anti-cancer agent. J Mol Struct. https://doi.org/10.1016/j.molstruc.2019.127486

27. Bijelic A, Aureliano M, Rompel A (2018) The antibacterial activity of polyoxometalates: structures, antibiotic effects and future perspectives. Chem Commun 54:1153-1169

28. Pisk J, Agustin D, Poli R (2019) Organic salts and merrifield resin supported [PM12O40]3-(M=Mo or W) as catalysts for adipic acid synthesis. Molecules 24:783

29. Liu X, Xu D, Wang Q, Zhang L (2018) Fabrication of 3D hierarchical byttneria aspera-like Ni@Graphitic carbon yolk-shell microspheres as bifunctional catalysts for ultraefficient oxidation/reduction of organic contaminants. Small. https://doi. org/10.1002/smll.201803188 
30. Dong H, Dai Y, Zhang X, Zhang Z, Fu S, Zhong Z (2017) The influence of amine structures on the stability and catalytic activity of gold nanoparticles stabilized by amine-modified hyperbranched polymers. Nanotechnology 29:55705

31. Godiya CB, Cheng X, Li D, Chen Z, Lu X (2018) Carboxymethyl cellulose/polyacrylamide composite hydrogel for cascaded treatment/reuse of heavy metal ions in wastewater. J Hazard Mater. https://doi.org/10.1016/j.jhazmat.2018.09.076

32. Afedzi TW, Yeoh FY, Yang MT, Yip ACK, Lin KYA (2019) A comparative study of hexacyanoferrate-based prussian blue analogue nanocrystals for catalytic reduction of 4-nitrophenol to 4-aminophenol. Sep Purif Technol 218:138-145

33. Deltcheff CR, Fournier M, Franck R, Thouvenot R (1983) Vibrational investigations of polyoxometalates. 2. Evidence for anion-anion interactions in molybdenum (V1) and tungsten (V1) compounds related to the Keggin structure. Inorg Chem 22:207-216

34. Yang $X$, Zhong $H$, Zhu Y, Jiang H, Shen J, Huang J, Li C (2014) Highly efficient reusable catalyst based on silicon nanowire arrays decorated with copper nanoparticles. J Mater Chem A 2:9040-9047

35. Kianpour G, Niasari MS, Emadi H (2013) Sonochemical synthesis and characterization of $\mathrm{NiMoO}_{4}$ nanorods. Ultrason Sonochem $20: 418-424$

36. Zonoz FM, Jamshidi A, Tavakoli S (2013) Preparation, characterization and electrochemical investigation of a new inorganicorganic hybrid material based on kegging-type polyixometalate and organic imidazole cation. Solid State Sci 17:83-89

37. Jing N, Jiang $X$, Wang $Q$, Tang $Y$, Zhang $P$ (2014) Attenuated total reflectance/Fourier transform infrared (ATR/FTIR) mapping coupled with principal component analysis for the study of in vitro degradation of porous polylactide/hydroxyapatite composite material. Anal Methods 6:5590-5595

38. Wienold J, Jentoft RE, Ressler T (2003) Structural investigation of the thermal decomposition of ammonium heptamolybdate by in situ XAFS and XRD. Eur J Inorg Chem 6:1058-1071

39. Sklar N, Senko ME, Post B (1961) Thermal effects in urea: the crystal structure at $-140^{\circ} \mathrm{C}$ and at room temperature. Acta Cryst 14:716-720

40. Troyanov SI, Morozov IV, Znamenkov KO, Korenev YM (1995) Synthesis and X-Ray structure of new copper(II) nitrates: $\mathrm{Cu}\left(\mathrm{NO}_{3}\right)_{2} \cdot \mathrm{H}_{2} \mathrm{O}$ and $\beta$-modification of $\mathrm{Cu}\left(\mathrm{NO}_{3}\right)_{2}$. Zeitschrift für anorganische und allgemeine Chemie 621:1261-1265

41. Feyst M, Molchanov VN, Kazanskij LP, Torchenkova EA, Spitsyn VI (1980) Zh Neorg Khim 25:733

42. Yu J, Ran J (2011) Facile preparation and enhanced photocatalytic $\mathrm{H}_{2}$-production activity of $\mathrm{Cu}(\mathrm{OH})_{2}$ cluster modified $\mathrm{TiO}_{2}$. Energy Environ Sci 4:1364

43. Fontecave M, Karapinar D, Tran NH, Ranjbar Sahraie N, Li J, Touati $\mathrm{N}$, Wakerley D (2019) Electroreduction of $\mathrm{CO}_{2}$ on single-site copper-nitrogen-doped carbon material: selective formation of ethanol and reversible restructuration of the metal sites. Angew Chem Int Ed. https://doi.org/10.1002/anie.201907994

44. Sun N, Wu A, Yu Y, Gao X, Zheng L (2019) Polyoxometalate-based photochromic supramolecular hydrogels with highly ordered spherical and cylindrical micellar nanostructures. Chem Eur J. https://doi.org/10.1002/chem.20190047

45. Yi H, Kuwahara Y, Mori K, Yamashita H (2018) Plasmonic metal/ $\mathrm{Mo}_{x} \mathrm{~W}_{1-x} \mathrm{O}_{3-y}$ for visible-light-enhanced $\mathrm{H}_{2}$ production from ammonia borane. J Mater Chem A 6:10932-10938

46. Brunauer S, Emmet PH, Teller E (1938) Adsorption of gases in multimolecular layers. J Am Chem Soc 60:309-319

47. Teng C, He J, Zhu L, Ren L, Chen J, Hong M, Wang Y (2015) Fabrication and characterization of monodisperse magnetic porous nickel microspheres as novel catalysts. Nanoscale Res Lett 10:384
48. Papadas IT, Subrahmanyam KS, Kanatzidis MG, Armatas GS (2015) Templated assembly of $\mathrm{BiFeO}_{3}$ nanocrystals into 3D mesoporous networks for catalytic applications. Nanoscale 7:5737-5743

49. Fang D, Li X, Liu H, Xu W, Jiang M, Li W, Fan X (2017) BiVO ${ }_{4}^{-r G O}$ with a novel structure on steel fabric used as high-performance photocatalysts. Sci Rep 7:7979

50. Vyazovkin S, Burnham AK, Criado JM, Perez-Maqueda LA, Popescu C, Sbirrazzuoli N (2011) ICTAC Kinetics committee recommendations for performing kinetic computations on thermal analysis data. Thermochim Acta 520:1-19

51. Brown ME, Maciejewski M, Vyazovkin S, Nomen R, Sempere J, Burnham A, Opfermann J, Strey R, Anderson HL, Kemmler A, Keuleers R, Janssens J, Desseyn HO, Li CR, Tang TB, Roduit B, Malek J, Mitsuhashi T (2000) Computational aspects of kinetic analysis. Part A: the ICTAC kinetics project: data, methods, and results. Thermochim Acta 355:125-143

52. Flynn JH (1983) The isoconversional method for determination of energy of activation at constant heating rates. J Therm Anal Calorim 27:95-102

53. Kissinger HE (1957) Reaction kinetics in differential thermal analysis. Anal Chem 29:1702-1706

54. Vyazovkin S, Dollimore DJ (1996) Linear and nonlinear procedures in isoconversional computations of the activation energy of nonisothermal reactions in solids. J Chem Inf Comput Sci 36:42-45

55. Vyazovkin S, Wright CA (2000) Estimating realistic confidence intervals for the activation energy determined from thermoanalytical measurements. Anal Chem 72:3171-3175

56. Farjas J, Roura P (2011) Isoconversional analysis of solid-state transformations. A critical review. Part I. Single step transformations with constant activation energy. J Therm Anal Calorim 105:757-766

57. Vyazovkin S, Wight CA (1997) Kinetics in solids. Annu Rev Phys Chem 48:125-149

58. Friedman HL (1964) Kinetics of thermal degradation of charforming plastics from thermogravimetry. Application to a phenolic plastic. J Polym Sci Part C Polym Symp 6:183-195

59. Surender R, Mahendran A, Thamaraichelvan A, Alam S, Vijayakumar CT (2013) Curing studies of bisphenol A based bismaleimide and cloisite 15a nanoclay blends using differential scanning calorimetry and model-free kinetics. J Appl Polym Sci 128:712-724

60. Sarannya V, Rishwana SS, Mahalakshmy R, Mahendran AR, Surender R, Vijayakumar CT (2019) Synthesis and thermal studies of bis(isomaleimide)/bisphenol A and ortho novalac blends. J Elastom Plast. https://doi.org/10.1177/0095244319871683

61. Rishwana SS, Mahendran A, Vijayakumar CT (2015) Studies on structurally different benzoxazines based on diphenols anddiamines: kinetics of thermal degradation and TG-FTIR studies. Thermochim Acta 618:74-87

62. Dhanalakshmia JP, Raj MA, Vijayakumar CT (2016) Thermal degradation kinetics of structurally diverse poly(bispropargyl ethers-bismaleimide) blends. Chin J Polym Sci 34:253-267

63. Zhang X, Su Z (2012) Polyelectrolyte-multilayer-supported Au@ Ag core-shell nanoparticles with high catalytic activity. Adv Mater 24:4574-4577

64. Sahoo GP, Basu S, Samanta S, Misra A (2014) Microwave-assisted synthesis of anisotropic gold nanocrystals in polymer matrix and their catalytic activities. J Exp Nanosci 10:690-702

65. Wu XQ, Wu XW, Huang Q, Shen JS, Zhang HW (2015) In situ synthesized gold nanoparticles in hydrogels for catalytic reduction of nitroaromatic compounds. Appl Surf Sci 331:210-218

66. Sudhakar P, Soni H (2018) Catalytic reduction of nitrophenols using silver nanoparticles-supported activated carbon derived from agro-waste. J Environ Chem Eng 6:28-36 
67. Nguyen TB, Huang CP, Doong R (2018) Enhanced catalytic reduction of nitrophenols by sodium borohydride over highly recyclable Au@graphitic carbon nitride nanocomposites. Appl Catal B Environ. https://doi.org/10.1016/j.apcatb.2018.08.035

68. Huang G, Yang L, Ma X, Jiang J, Yu SH, Jiang HL (2016) Metalorganic framework-templated porous carbon for highly efficient catalysis: the critical role of pyrrolic nitrogen species. Chem Eur J 22:3470-3477

69. Nadgorny M, Xiao Z, Chen C, Connal LA (2016) Three-dimensional printing of $\mathrm{pH}$-responsive and functional polymers on an affordable desktop printer. Appl Mater Interfaces 8:28946-28954

70. Yang Y, Mao Y, Wang B, Meng X, Han J, Wang C, Yang H (2016) Facile synthesis of cubical Co3O4 supported Au nanocomposites with highly activity for the reduction of 4-nitrophenol to 4-aminophenol. RSC Adv 6:32430-32433

71. Zuoyi X, Zhai S, An Q, Wang X, Ma X, Zhao Z, Bai H (2017) Monolithic $\mathrm{Cu} / \mathrm{C}$ hybrid beads with well-developed porosity for reduction of 4-nitrophenol to 4-aminophenol. New J Chem 41:13230-13234

72. Mondal S, Rana U, Bhattacharjee RR, Malik S (2014) One pot green synthesis of polyaniline coated gold nanorods and its applications. RSC Adv 4:57282-57289

73. Veerakumar P, Thanasekaran P, Lin KC, Liu SB (2017) Well-dispersed rhenium nanoparticles on three-dimensional carbon nanostructures: efficient catalysts for the reduction of aromatic nitro compounds. J Colloid Interface Sci 506:271-282

74. Herves P, Lorenzo MP, Marzan LML, Dzubiella J, Lu Y, Ballauff M (2012) Catalysis by metallic nanoparticles in aqueous solution: model reactions. Chem Soc Rev 41:5577-5587

Publisher's Note Springer Nature remains neutral with regard to jurisdictional claims in published maps and institutional affiliations. 